\title{
Convergência Tecnológica e a Formação de Novos Tipos de Alianças Estratégicas: uma análise do desenvolvimento dos Personal Digital Assistant (PDAs)*
}

\section{Danilo Eugênio Amorim}

Mestre em Desenvolvimento Econômico pelo Programa de Pós-graduação em

Desenvolvimento Econômico da Universidade Federal do Paraná

Walter Tadahiro Shima

Professor do Departamento de Economia da Universidade Federal do Paraná

Recebido: 6/7/2005 Aprovado: 8/6/2006

RESUMO

As associações entre empresas não são fato novo. Todavia, principalmente a partir da década de 1980, as influências da internacionalização da competição e as pressões tecnológicas impuseram grandes mudanças na conformação desses arranjos. Verificou-se recentemente um forte crescimento dos acordos cooperativos entre firmas. Aqueles acordos que priorizam estratégias de aperfeiçoamento em termos de competência tecnológica passaram a ter grande participação na concorrência. Este artigo usa o conceito de redes de empresas, que permite a percepção de que é viável basear-se na competência de outras empresas para concorrer com maior eficácia, para a análise da natureza das alianças estratégicas

\footnotetext{
* Os autores agradecem aos pareceristas anônimos da RBI, uma vez que, reconhecem amplamente que as sugestões feitas engrandeceram bastante $o$ artigo. Por meio das sugestões das bibliografias, os autores conseguiram sistematizar, no artigo, aspectos relevantes do conhecimento aplicado que possuíam. Entretando, possíveis fal has remanescentes são de estrita responsabilidade dos autores.
} 
a partir da convergência tecnológica em multimídia. Mais especificamente, o artigo analisa a formação da joint venture entre a fabricante de celulares Ericsson e a fabricante dos produtos eletrônicos de consumo amplo Sony para o desenvolvimento da terceira geração de celulares.

Palavras-Chave | Alianças Estratégicas; Personal Digital Assistant; Microeletrônica; Comunicação Móvel; Sony-Ericsson

Códigos JEL | L20; L63

\section{ABSTRACT}

The associations between companies are not a recent fact. However, the internationalization of competition and technological pressures have imposed great changes on the conformation of such arrangements since the 1980s. Recently, there has been a rapid growth in the cooperative agreements between firms. The agreements that prioritize strategies for improvement in terms of technological competence have had a great deal of participation in the competition. This article uses the concept of networking, which allows the perception that alliances with other companies' competences to compete more efficiently is far more viable, to analyze the true nature of strategic alliances based on the technological convergence into multimedia. More specifically, the paper analyzes the formation of a joint venture between the supplier of cell-phones, Ericsson, and the supplier of electronic products for vast consumption, Sony, in order to develop a third generation of cell-phones.

KeYwords I Strategic Alliances; Personal Digital Assistant; Microelectronics; Mobile Communication; Sony-Ericsson

JEL-CODES | L20; L63 


\section{Introdução}

Mercados de computadores e de comunicações estão em processo de redefinição. No cerne desse processo encontram-se dois fenômenos. De um lado tem-se o surgimento de uma nova classe de computadores miniaturizados. Por outro, há os avanços na capacidade de digitalização de voz, dados, texto e imagens. Conjuntamente, eles abrem novas oportunidades de negócios relacionadas ao mundo digitalizado em que fabricantes de aparelhos e desenvolvedores de redes de comunicação, além da diversificação dos serviços relacionados às atividades telemáticas, vêem o entretenimento móvel como um aspecto importante para o futuro deste mercado: consumidores usarão seus celulares não apenas para estabelecer comunicação de voz, mas também para trocas e acesso virtual a dados e conteúdos de entretenimento (música, imagem e vídeo).

Essas novas possibilidades técnicas estão moldando um novo ambiente competitivo em que as firmas estão se posicionando para enfrentar as fortes incertezas tanto tecnológicas como de mercado. Por conseguinte, tem sido crescente o número de arranjos colaborativos, envolvendo inclusive firmas rivais, pressionados pela integração de conhecimentos provenientes de diferentes disciplinas científicas e/ou áreas tecnológicas. Assim, firmas de segmentos totalmente diferentes unem competências e convergem para a formação de alianças. Nesse sentido, a difusão das tecnologias genéricas associadas ao novo paradigma, em especial as tecnologias da informação, com a conseqüente convergência tecnológica impõe uma nova estrutura competitiva que traz firmas de segmentos inimagináveis para a competição. No auge do desenvolvimento das tecnologias analógicas, por exemplo, era inimaginável que a Sony pudesse ter alguma relação com a comunicação de voz, assim como a Ericsson com a imagem. Porém, quando som, imagem e voz se tornaram uma única matériaprima, essas firmas puderam buscar algum tipo de arranjo cooperativo para explorar competências mútuas para a produção de multimídia em geral.

Dentro deste contexto, o objetivo deste artigo é analisar a natureza das alianças estratégicas a partir da convergência tecnológica em multimídia. Mais especificamente, como exemplo, será analisada a formação da joint venture entre a fabricante de celulares Ericsson e a fabricante dos produtos eletrônicos de consumo amplo Sony, para o desenvolvimento da terceira geração de celulares. 
Por meio desse caso, pretende-se entender como digitalização propicia a cooperação entre agentes econômicos de segmentos totalmente diferentes e define novas estruturas competitivas.

Neste intuito, este trabalho compõe-se de mais quatro seções além desta introdução. $\mathrm{Na}$ segunda seção é apresentada a abordagem de redes de firmas dentro da análise econômica e suas principais características. Na terceira seção são apresentadas as características do mercado de aparelhos PDA (Personal Digital Assistant), no que se refere à discussão sobre as gerações de comunicação móvel, convergência e padrões tecnológicos. Na quarta seção analisam-se as implicações da evolução do mercado desses aparelhos e da trajetória tecnológica das firmas para o caso da aliança recente entre as firmas Sony e Ericsson. Pretende-se aqui discutir os possíveis desdobramentos desse empreendimento em termos da trajetória tecnológica das firmas envolvidas e, por outro lado, a influência de suas trajetórias tecnológicas sobre a configuração do acordo. Por fim, na quinta seção são apresentadas algumas conclusões.

\section{Conceito e características da rede de firmas}

Um tema recorrente na literatura econômica, mais especificamente por parte da economia industrial, tem sido o crescente número de diversos tipos de arranjos colaborativos envolvendo organizaçôes distintas. Essa cooperação entre empresas e outras organizações e instituições, no âmbito da teoria econômica, tem sido estudada dentro de duas concepçóes distintas (Britto, 2002): na primeira delas o conceito de rede é utilizado no tratamento de problemas de natureza alocativa recorrentemente enfrentados pela ciência econômica, estando relacionado à noção de "externalidades em rede" enquanto princípio orientador da análise; no outro tipo de abordagem, as estruturas em rede constituem-se no objeto específico de investigação, isto é, esta abordagem referencia o conceito de rede a um tipo particular de instituição, com a capacidade de coordenar a realização de atividades econômicas. Coerentemente, como afirma Britto (2002), neste último enfoque a análise centra-se nos processos de estruturação e transformação destas redes a partir de estímulos internos e externos, e não no impacto que a formação destas estruturas acarreta sobre a dinâmica de comportamento dos diferentes mercados. 
O ponto de partida fundamental é a necessidade de entender o que é uma rede de firmas, seus elementos estruturais constituintes e os mecanismos de transformação, reprodução e fortalecimento dessas estruturas ao longo do tempo. Esses elementos são: os pontos, as posições, as ligações e os fluxos (Britto, 1999).

Os pontos representam o conjunto de agentes que definem a rede. Estes pontos são, portanto, as firmas, que possuem características ou atributos distintos. Estes atributos, associados aos diferentes pontos que estão integrados na rede pelo estabelecimento de vínculos sistemáticos entre eles, definem os padrões de interdependência e complementaridade recíprocos entre as unidades inseridas nesses arranjos. A complementaridade entre as competências dos agentes, como se destaca, desempenha papel relevante na caracterização da estrutura do arranjo (Britto, 1999).

As posiçôes definem como os diferentes pontos se localizam no interior da estrutura. Em particular, estas posições estão associadas a uma determinada divisão do trabalho entre as firmas, o que reforça a interdependência entre os agentes no interior das redes (Britto, 1999).

As ligaçôes, enquanto elementos morfológicos das redes referem-se ao mapa dos relacionamentos entre os diversos pontos contidos na rede, com especial atenção sendo dada à forma e ao conteúdo destas articulações. Quanto à forma dos relacionamentos, o ponto central é o arcabouço contratual que regula as relaçôes entre os agentes, principalmente definindo mecanismos de coordenação e de prevenção contra possíveis comportamentos oportunistas por parte dos agentes, além de reforçar o comprometimento com os objetivos das partes envolvidas. O conteúdo se refere aos objetivos do relacionamento não excludentes entre si, que podem ser mercadológicos, de integração de etapas ao longo de uma cadeia produtiva ou de realização de esforço tecnológico conjunto (Britto, 1999).

Finalmente, os fluxos referem-se à natureza e ao conteúdo dos estímulos que circulam entre os distintos pontos da rede. Os diferentes fluxos presentes nas redes de firmas podem ser classificados em tangíveis e intangíveis. Os fluxos tangiveis são mais fáceis de serem identificados qualitativa e quantitativamente em termos de volume e valor. Por outro lado, os fluxos intangiveis correspondem às informaçôes que conectam as diversas firmas integradas à estrutura em rede. Contrariamente aos fluxos tangíveis, os fluxos intangíveis são mais difíceis de 
se investigar devido à sua imaterialidade. No paradigma das genéricas Tecnologias da Informação (TIs), é crescente a capacidade de codificação de informações e conhecimentos, embora uma parcela expressiva destes ainda se constitua de elementos tácitos e, portanto, nem sempre passíveis de transferência. Assim, o grau de codificação das informações transmitidas pode variar bastante. Além disso, é preciso considerar o caráter idiossincrático do processo de aprendizado, pois eles são próprios das organizaçōes e seus ambientes, sendo assim difíceis de serem copiados por outras estruturas (Britto, 1999).

Três impactos distintos associados à consolidação destes arranjos são considerados (Britto, 1999): i) impactos diretos associados à esfera técnico-produtiva associados a economias de escala e escopo, bem como à diminuição de custos e à geração de externalidades ${ }^{1}$ indutoras de um maior nível de eficiência; ii) impactos indiretos associados à consolidação de instâncias de coordenação das decisões produtivas e tecnológicas dos agentes inseridos na rede, que permitem um melhor enfrentamento da incerteza subjacente à concorrência intercapitalista; e, finalmente, iii) impactos dinâmicos, que dizem respeito ao aprofundamento de mecanismos interativos de aprendizado, que reforçam a capacitação tecnológica e alavancam o potencial inovativo dos agentes integrados ao arranjo.

Essa caracterização é importante porque permite entender a intensa adoção dessa nova forma de organização industrial ocorrida nas últimas décadas, inserida e apoiada em novas bases tecnológicas, suportada pela microeletrônica e fortemente difundida nos diversos setores econômicos. Contudo, a cooperação interindustrial não é um fenômeno novo. $\mathrm{Na}$ verdade esses acordos são formas de geração de vantagens competitivas para as empresas neles inseridas e que evoluem com o contexto histórico em que se encontram. Assim, os acordos de cooperação entre firmas passaram por importantes mudanças no seu modo de operação a partir da década de 1980, impulsionados principalmente pela consolidação do novo paradigma tecnológico das tecnologias de informação (Freeman, 1991; Hagedoorn, 1990; Narula \& Hagedoorn, 1999). Quantitativamente, o que se verificou foi o grande crescimento de novos acordos

\footnotetext{
Britto (2002) distingue os seguintes tipos de externalidades em rede: i) externalidades técnicas associadas a impactos diretos nas funções de produção dos membros da rede; ii) externalidades pecuniárias associadas à redução dos preços de insumos e outros fatores; iii) externalidades tecnológicas especificamente associadas a efeitos do tipo spill-over; iv) externalidades de demanda presentes nas situações em que a demanda individual é influenciada pela demanda agregada do mesmo bem.
} 
cooperativos entre firmas. Já qualitativamente, ocorreu um movimento de mudança na importância relativa das diferentes formas de cooperação. Aqueles acordos que priorizavam estratégias puramente minimizadoras de custos (impactos estáticos) tornaram-se cada vez menos constantes em detrimento do aumento daqueles que visam aperfeiçoamento em termos de competência tecnológica (impactos dinâmicos). Entre os fatores que ajudam a explicar estas mudanças no padrão de colaboração nas redes de inovação, pode-se citar a crescente complexidade sistêmica do desenvolvimento tecnológico, cuja interdisciplinaridade requer a aglutinação de múltiplas competências. Na verdade, a importância dos critérios de desempenho estático (custos) persiste; contudo, a geração de impactos dinâmicos passou a ser fator preponderante em arranjos cooperativos, principalmente naqueles que envolvem agentes de setores de grande dinamismo tecnológico.

Como destaca Hagedoorn (2002), as importantes mudanças industriais e tecnológicas ocorridas nas décadas de 1980/1990 impulsionaram a formação de novos acordos estratégicos para o desenvolvimento tecnológico, que se concentraram principalmente em um quadro amplo de setores intensivos em tecnologia (Gráfico 1).

Ademais, nos dias atuais são muito comuns produtos e serviços que incorporam habilidades e conhecimentos tecnológicos específicos de áreas diversas (onde a inovação em determinados componentes de um produto ou processo podem afetar o sistema como um todo). Diante dessa intensa interdisciplinaridade tecnológica, as firmas precisam manter uma base de conhecimentos técnicos para conseguirem monitorar e explorar avanços em cada uma dessas fronteiras e converter novas possibilidades abertas em vantagens competitivas. Na realidade, a evolução de muitos produtos e serviços se expressa na dinâmica conjunta de várias trajetórias tecnológicas, o que impõe fortes demandas sobre as atividades de P\&D, internas e/ou externas. Como conseqüência, esses produtos e serviços multitecnológicos podem gerar situações caracterizadas por mudanças a diferentes taxas e em direçóes diversas nas diferentes tecnologias que suportam seus componentes individualmente. ${ }^{2}$ Assim, quando as inovações apresentam um

\footnotetext{
2 Este fenômeno, isto é, as especificidades setoriais e tecnológicas, podem ser expressas nos diferentes graus de oportunidades tecnológicas, de apropriabilidade e na complexidade da base de conhecimentos necessários. Para uma rápida revisão das características dos regimes tecnológicos, cf. Dosi et al. (1993), por exemplo.
} 
GRÁFICO 1

Participação (\%) das indústrias de alta tecnologia no estabelecimento de novas parcerias de P\&D (1960/1998)

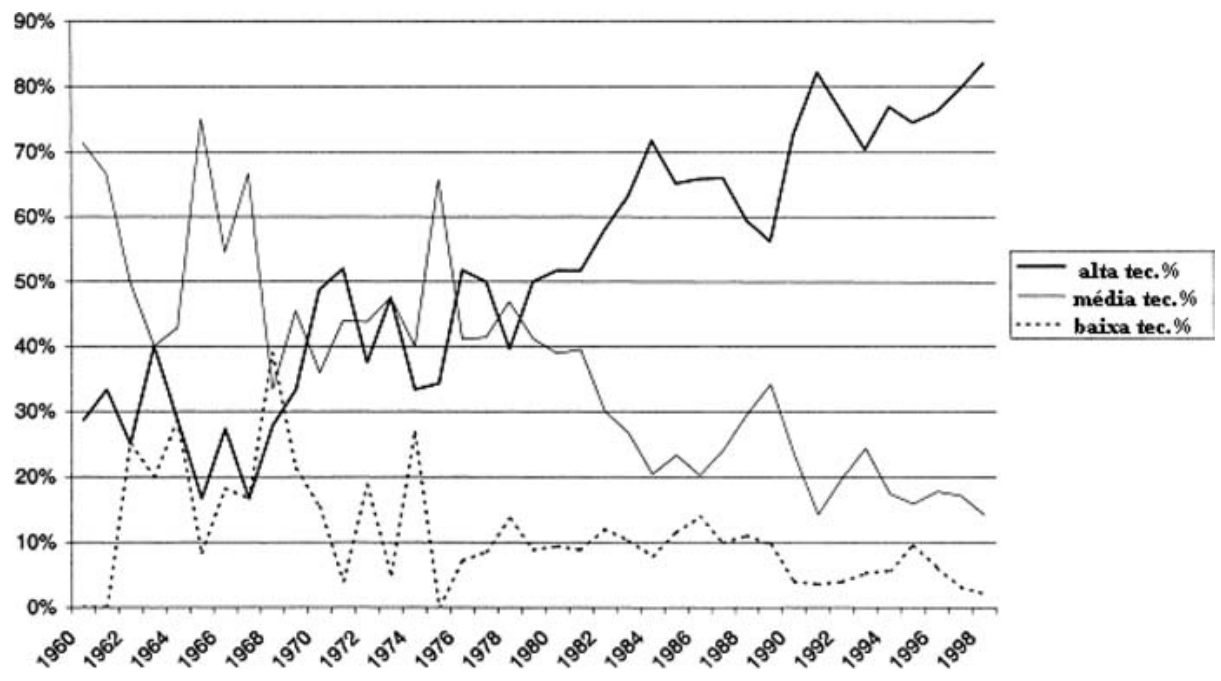

Fonte: Hagedoorn (2002).

caráter eminentemente sistêmico, envolvendo a integração de conhecimentos provenientes de diferentes disciplinas científicas e/ou áreas tecnológicas, as firmas geralmente se defrontam com desequilíbrios e estrangulamentos tecnológicos (Britto, 1999). Quando isso acontece, salientam Brusoni e Prencipe (2001), as organizaçôes precisam desenvolver mecanismos de coordenação para acomodar as mudanças nas áreas que causam desequilíbrios e tem efeito cascata sobre outras. E quando o número de campos técnico-científicos relevantes se eleva e novos requisitos em termos de competências críticas aparecem, como salientam estes autores, reforça-se a importância da cooperação tecnológica com outros agentes. ${ }^{3}$ Assim, através de arranjos cooperativos as firmas se beneficiam das vantagens da integração e da especialização. Ou seja, a especialização tecnológica das firmas e a suas ligações umas às outras é uma resposta à necessidade de desenvolvimento de competências tecnológicas em áreas industriais distintas (Gomes-Casseres, 1994). Portanto, esse expediente

\footnotetext{
3 Para uma discussão sobre o efeito de mudanças tecnológicas sobre o processo de integração e/ou cooperação para o desenvolvimento de produtos sistêmicos, cf. Henderson \& Clark (1990), Prencipe (1997) e Brusoni et al. (2001).
} 
QUADRO 1

Principais tipos de redes

Principais tipos de arranjos cooperativos

1. joint-venture e Corporações de Pesquisa;

2. acordos de cooperação em P\&D;

3. acordos de intercâmbio tecnológico;

4. investimento direto motivado por fatores tecnológicos;

5. acordos de licenciamento;

6. redes de subcontratação, de compartilhamento da produção e de fornecedores;

7. associações de pesquisa;

8. programas de pesquisa patrocinados pelo Governo;

9. bancos de dados computadorizados e redes de valor adicionado para intercâmbio técnico e científico;

10. outros tipos de redes, incluindo redes informais.

Fonte: Freeman (1991).

(redes) permite, por meio da interação e cooperação, explorar a complexidade dos conhecimentos envolvidos nas novas tecnologias e o desenvolvimento de capacidades e acesso a recursos que, de outra forma, dificilmente seriam obtidos (Castells, 2000).

O Quadro 1 expõe os principais tipos de redes. Vale dizer, essas categorias de arranjos cooperativos não são mutuamente exclusivos. Na verdade, muitas vezes as firmas estão envolvidas, simultaneamente, em vários destes tipos de arranjos de cooperação com outras firmas, variando ainda seu nível de formalidade, desde uma joint-venture a acordos essencialmente informais.

Uma das variantes mais importantes do fenômeno de redes é a conformação das alianças estratégicas. Alianças estratégicas podem ser entendidas como uma parceria que tem como objetivo aumentar a eficácia das estratégias competitivas das organizações que fazem parte do arranjo (Hagedoorn \& Schakenraad, 1992). Isto seria alcançado por meio do intercâmbio mútuo e benéfico de tecnologias, qualificações ou produtos. Suas características principais 
são: $i$ ) a conservação da independência das firmas depois da formação da aliança; ii) o compartilhamento dos benefícios e o controle do desempenho das tarefas combinadas - apontado como o traço mais distintivo das alianças e complicador da gestão; iii) a continuidade na contribuição por parte das firmas parceiras nas áreas estratégicas cruciais do arranjo (Yoshino \& Rangan, 1997). Por conseguinte, o caráter estratégico das ligações entre os pontos da rede, compreendendo cooperação e competição, é o seu principal traço distintivo (Narula \& Hagedoorn, 1999). Ademais, fica claro a importância de se ter em mente o aspecto estratégico deste tipo de arranjo cooperativo, pois os objetivos estratégicos das firmas envolvidas influenciam de forma determinante a conformação da estrutura do arranjo interorganizacional e a relação deste com o ambiente em que está inserido.

Há de se considerar também a necessidade de recuperar os custos da inovação num menor prazo em função dos problemas impostos à apropriação do retorno dos investimentos em novos produtos que se tornam obsoletos rapidamente. Por conseguinte, como meio de recuperar os custos da inovação, é cada vez maior o número de empresas que procuram construir redes externas de alianças internacionais, além das nacionais, para manter as vantagens conquistadas e expandir seu mercado internacionalmente. Conseqüentemente, as alianças estratégicas são, em termos gerais, meios das firmas avançarem na internacionalização de suas atividades, principalmente quando se destaca a diferença na distribuição espacial de recursos que afetam a capacidade de geração de inovações, o que acentua a tendência de especialização na produção de firmas e regiōes (Hagedoorn \& Schakenraad, 1992). ${ }^{4}$ Porém, quando se analisa a articulação entre países desenvolvidos e aqueles menos desenvolvidos, conforme ilustra o Gráfico 2, verifica-se uma forte concentração geográfica de acordos de cooperação tecnológica entre os primeiros em detrimento da marginalização dos últimos. De fato, quase 95\% delas englobam firmas da tríade (EUA, Europa e Japão) (Narula \& Hagedoorn, 1999; Hagedoorn, 2002).

Três restrições fundamentais devem ser consideradas não obstante as vantagens potenciais associadas às alianças estratégicas (Gomes-Casseres, 1994):

\footnotetext{
4 Vale ressaltar que, apesar desse ser um fenômeno caracteristicamente ao nível da firma, fatores nacionais desempenham papel importante na determinação do nível de participação dos países em alianças. Há evidências de que firmas de países pequenos têm uma tendência a um maior envolvimento em investimentos internacionais quando comparadas com firmas de países maiores, principalmente devido à insuficiência de demanda para se alcançar a escala mínima. Além disso, países menores são mais especializados em determinados setores e nichos e por isso, para se diversificarem, são obrigados a estabelecer vínculos com outras localidades (Narula \& Hagedoorn, 1999).
} 
GRÁFICO 2

Distribuição das parcerias em P\&D por regiões econômicas (1960-1998)

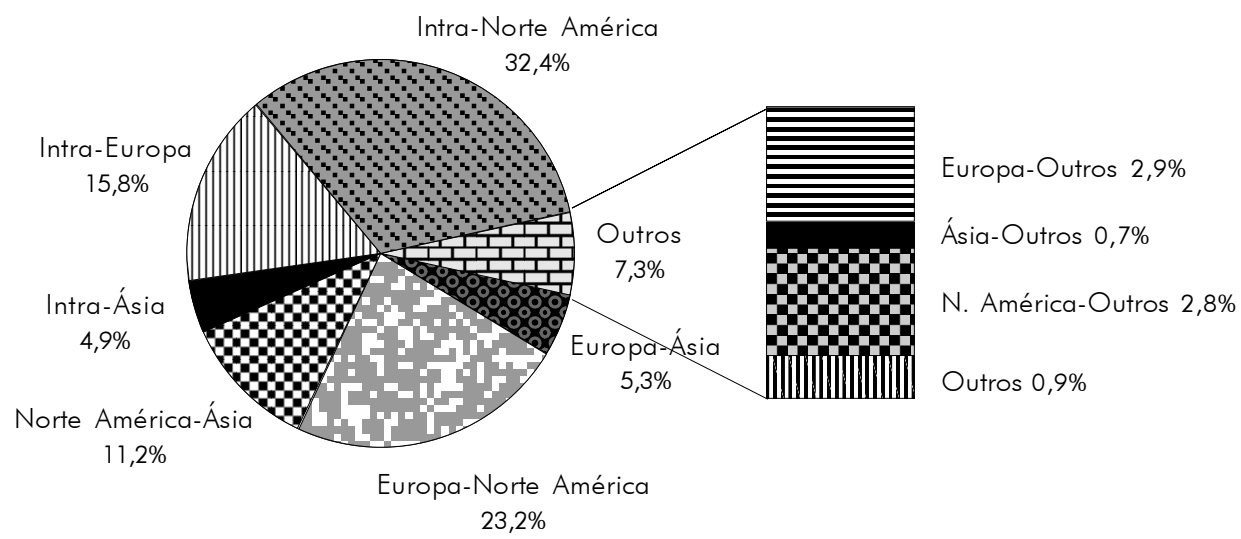

Fonte: Hagedoorn (2002).

(i) a restrição organizacional, derivada da crescente dificuldade de se coordenar as operaçôes do grupo, na medida em que a cada nova aliança mais e mais parceiros precisam ser consultados; (ii) o congestionamento estratégico, que resulta do número limitado de parceiros disponíveis; (iii) a dependência decorrente da perda de parte do poder de controle das companhias aliadas sobre suas açóes, de forma que o crescimento da rede de alianças pode, gradualmente, condicionar a trajetória da firma à trajetória da rede. O grande desafio para cada aliado é encontrar um equilíbrio entre a interdependência interorganizacional e a autonomia individual de decisão. Ou seja, a grande dificuldade está em definir em que medida os objetivos e a independência, próprios de cada agente, vão ser influenciados pela aliança. Dependendo do grau de dependência por parte de um parceiro com relação aos demais, não só a autonomia decisória e a flexibilidade podem ser reduzidas, mas principalmente, também a capacidade de usar esses recursos em empreendimentos alternativos. Assim, na medida em que as firmas passam a ter suas histórias individuais cada vez mais ligadas à evolução da aliança, pode ocorrer da firma ter que subordinar suas próprias decisões às decisões impostas pelos demais aliados.

Como destaca Gomes-Casseres (1994), para avaliar os benefícios relativos e os custos potenciais das alianças, a premissa subjacente é a de que uma 
empresa deve tirar mais valor de uma atividade cooperativa do que se agisse sozinha, conservando sua flexibilidade estratégica; caso contrário, a aliança não faz sentido. Por isso, apesar da grande expansão verificada, há aqueles autores que argumentam que haveria uma tendência à gradual estagnação ou até mesmo declínio no padrão de crescimento desses arranjos, na medida em que as firmas aprendem que tais acordos cooperativos implicam grandes riscos e não solucionam a maioria dos seus problemas (Hagedoorn \& Schakenraad, 1992; Narula e Hagedoorn, 1999). ${ }^{5}$ No entanto, as alianças em TIs têm-se constituído numa exceção a essa tendência. Na década de 1980, os desenvolvimentos nessas áreas acentuaram as possibilidades da construção de uma rede complexa, interligando subcampos até então relativamente separados como telecomunicaçôes, automação industrial e computadores e mostrando a necessidade de alianças estratégicas entre firmas de diferentes campos de TIs (Hagedoorn \& Shakenraad, 1992). Nessa direção, para o período 1989-2000, Knoke, Yang e Granados (2002) apontam o expressivo aumento no número de alianças e no número médio de alianças por organização, tendo como a principal razão a necessidade de adaptar produtos e integrar serviços das diferentes companhias (as alianças subiram de $14 \%$ para $34 \%$ no período analisado).

\section{A convergência tecnológica e o surgimento do mercado de PDAS}

\subsection{A evolução das gerações dos padrões em comunicação móvel}

Apesar dos serviços de telecomunicações móveis terem emergido comercialmente apenas recentemente, verificou-se a explosão mundial de sua demanda somente a partir de meados da década de 1990 (Banerjee \& Ros, 2004). ${ }^{6} \mathrm{~A}$ trajetória do desenvolvimento da comunicação móvel pode ser entendida a

\footnotetext{
5 Entre os autores que sugerem que os acordos de cooperação como a uma forma organizacional de grande importância no novo paradigma, Castells (2000), por exemplo, afirma que "com a rápida transformação tecnológica, as redes - não as firmas - tornaram-se a unidade operacional real" (p.191). Já na visão acima, em que arranjos cooperativos sãoo reflexo passageiro da mudança do paradigma, as firmas se tornariam gradualmente mais familiarizadas com as novas tecnologias e, dessa forma, tenderiam a internalizar algumas redes antes sujeitas a acordos cooperativos. Isto é, haveria uma reconcentração industrial. Para uma síntese dessa oposição sobre a natureza permanente ou de transição da cooperação em rede como uma nova forma organizacional, cf. Freeman (1991).

6 Nos países escandinavos firmas e agências do governo já cooperavam desde a década de 1950 para o desenvolvimento de seus sistemas de comunicação móvel, fundamentalmente devido às dificuldades de instalação da infra-estrutura da rede de telecomunicação fixa em regiões de difícil acesso (Funk \& Methe, 2001).
} 
QUADRO 2

Evolução dos padrões globais de comunicação móvel

\begin{tabular}{|c|c|c|c|c|}
\hline $\begin{array}{l}\text { Geração da } \\
\text { Tecnologia }\end{array}$ & $\begin{array}{l}\text { Padrão de } \\
\text { comunicação }\end{array}$ & $\begin{array}{l}\text { Região ou país } \\
\text { de origem }\end{array}$ & Características & $\begin{array}{l}\text { Tecnologia } \\
\text { de rádio }\end{array}$ \\
\hline \multirow[t]{4}{*}{$\begin{array}{l}1^{a} \text { Geraçãao } \\
\text { (Analógico) }\end{array}$} & AMPS & América do Norte (1983) & Apenas voz & FDMA \\
\hline & TACS & Grã-Bretanha (1985) & & \\
\hline & NMT & Escandinávia (1981) & & \\
\hline & $\begin{array}{l}\text { Padrão-proprietário } \\
\text { da NTT }\end{array}$ & Japão & & \\
\hline \multirow[t]{4}{*}{$\begin{array}{l}2^{a} \text { Geraçãã } \\
\text { (Digital) }\end{array}$} & GSM & Europa (1992) & $\begin{array}{l}\text { Voz e dados } \\
\text { (até } 9.6 \mathrm{~kb} / \mathrm{s} \text { ) }\end{array}$ & $\begin{array}{l}\text { TDMA } \\
\text { (+ CDMA) }\end{array}$ \\
\hline & DAMPS & EUA (1993) & & \\
\hline & CDMAOne & EUA e Coréia (1996) & & \\
\hline & PDC & Japão (1993) & & \\
\hline \multirow{2}{*}{$\begin{array}{l}\text { PCS (Digital) } \\
3^{a} \text { Geração } \\
\text { (Digital) }\end{array}$} & PHS & Japão (1995) & $\begin{array}{l}\text { Voz e dados } \\
\text { (até } 2 \mathrm{Mb} / \mathrm{s} \text { ) }\end{array}$ & $\begin{array}{l}\text { CDMA } \\
\text { (+ TDMA) }\end{array}$ \\
\hline & W-CDMA & Japão (2001) & & \\
\hline
\end{tabular}

Fonte: Funk \& Methe (2001) e Kano (2000), adaptado pelos autores.

partir da classificação de três geraçôes. A primeira geração (1G) de serviços públicos de comunicação móvel, no início dos anos 1980, usava a tecnologia analógica FDMA (Frequency Division Multiple Access) de transmissão de voz por meio de sinais de rádio entre os celulares e as estações de rádio (Kano, 2000). Nessa 1G, existiam padrões regionais: na Europa vigorava o padrão NMT, nos EUA o AMPS e no Japão o padrão-proprietário da NMT. Fundamentalmente, essa geração se caracterizou pela baixa taxa de penetração devido aos elevados preços e à limitada qualidade dos serviços e capacidade dos aparelhos, que eram muito grandes e pesados para serem considerados portáteis (Banerjee \& Ros, 2004). O Quadro 2 sintetiza a evolução dos diversos padrões tecnológicos da comunicação móvel. 
$\mathrm{Na}$ década de 1990, surgiu a segunda geração (2G) de serviços públicos de comunicação móvel. Os aparelhos foram reduzidos significativamente em tamanho, permitindo de fato a portabilidade, enquanto a tecnologia analógica foi substituída pela digital que, conseqüentemente, permitiu também a transmissão de dados. As tecnologias de transmissão de rádio utilizadas foram a TDMA (Time Division Multiple Access) e a CDMA (Code Division Multiple Access). Em relação à taxa de transmissão dos dados, inicialmente essa taxa não ia além dos $9.6 \mathrm{~kb} / \mathrm{s}$. No entanto, avanços permitiram que ela alcançasse o nível de $200 \mathrm{~kb} / \mathrm{s}$ até o ano de 2000 . Novamente, mantêm-se os padrões-proprietário regionais de comunicação (Quadro 2). Na Europa prevalece o padrão GSM, nos EUA o padrão DAMPS e, no Japão, o PDC. Esses padrões, diante dos avanços significativos na qualidade e na capacidade dos serviços de comunicação móvel, conseqüentemente, aceleraram a difusão da telefonia móvel. Note-se na Tabela 1 as elevadas taxas de crescimento da telefonia móvel em relação à fixa no período 1995-2001, em todas as regióes do globo (Banerjee \& Ros, 2004). ${ }^{7}$

A terceira geração $(3 \mathrm{G})$ dos telefones celulares caracteriza-se pela maior mobilidade e velocidade de transmissão dos dados e a conexão com várias fontes de dados e de aplicações multimídia através do suporte ao acesso à internet. A tecnologia de transmissão de rádio utilizada é a W-CDMA (Wide band Code Division Multiple Access), uma técnica de rádio de banda larga. Com isso, as subscrições aos serviços de telefonia móvel estão crescendo ainda mais em função do declínio dos preços e melhor desempenho dos serviços, dos esforços de uniformização dos padróes tecnológicos e das promessas de serviços com velocidade de transmissão de dados de até $2 \mathrm{Mb} / \mathrm{s}$, o que permite o acesso à internet móvel e até a transmissão de vídeos (Banerjee \& Ros, 2004).

Note-se que nas primeiras gerações vigoraram padrões-proprietário regionais. Todavia, o aspecto de fundamental importância que deve ser destacado na evolução da $3 \mathrm{G}$ é a mudança na trajetória tecnológica do desenvolvimento dos padrões de comunicação. Ocorre que a partir da abertura dos mercados de telecomunicações e a expansão da demanda por serviços globais, a forte pressão

\footnotetext{
7 Todavia, como salientam Banerjee \& Ros (2004), há de se considerar as especificidades regionais das políticas de telecomunicações: nos países mais desenvolvidos, onde o setor de comunicações já se encontra bem avançado e, portanto, apresenta elevados níveis de densidade de telefones por habitantes, o crescimento tem-se dado de forma mais incremental; já os países menos desenvolvidos, apesar de apresentarem significativa elevação no número de usuários de telefonia móvel, ainda estão perseguindo a universalização de serviços convencionais de telefonia fixa.
} 
TABELA 1

Taxa de crescimento médio de linhas fixas e móvel no período 1995-2001

\begin{tabular}{lcc}
\hline Região/ País & Linhas Fixas & Linhas Móveis \\
\hline África & $9,20 \%$ & $84,70 \%$ \\
Américas & $5,00 \%$ & $33,20 \%$ \\
Canadá/ EUA & $2,90 \%$ & $25,10 \%$ \\
Resto das Américas & $11,90 \%$ & $67,40 \%$ \\
Ásia & $13,60 \%$ & $56,60 \%$ \\
Japão/ Coréia/ Hong-Kong/ Singapura & $3,40 \%$ & $40,80 \%$ \\
Resto da Ásia & $20,00 \%$ & $72,50 \%$ \\
Europa & $3,60 \%$ & $56,20 \%$ \\
Países da OCDE & $2,70 \%$ & $53,30 \%$ \\
Resto da Europa & $6,30 \%$ & $100,00 \%$ \\
Oceania & $2,00 \%$ & $31,80 \%$ \\
Mundo & $7,20 \%$ & $48,00 \%$ \\
\hline Fonte: Ban & & \\
\hline
\end{tabular}

Fonte: Baneriee \& Ros (2004).

para a interconexão das redes de comunicação impôs às operadoras a quebra de suas estratégias de lock-in e dependência por meio de padrões-proprietário contra a busca de padrões abertos ou compatíveis. Mais especificamente, com a crescente demanda de comunicação móvel internacional, o desenvolvimento atual da telemática tem como tendência o desenvolvimento de padrões abertos, cuja ênfase á a busca de maior velocidade e qualidade na transmissão de informações muito pesadas (as aplicações multimídia) por uma rede de telefonia móvel capaz de manter o mesmo número de chamada dos aparelhos ao redor do mundo (Kano, 2000). Além disso, a crescente complexidade dos aparelhos e da infraestrutura, com seus impactos sobre os custos de P\&D, pressionaram para a 
obtenção de economias de escala, o que somente seria possível com a fixação de padrões comuns (Bekkers et al., 2002).

Nessa nova tendência de difusão desse padrão global, Japão e Europa adotaram uma estratégia conjunta de criar um comitê cuja tarefa é desenvolver e propor um padrão global $3 \mathrm{G}$ que seria apreciado pela International Telecommunications Union (ITU). ${ }^{8}$ Esse esforço conjunto centrou-se na consolidação do padrão GSM. Ericsson e Nokia colaboraram fortemente com a NTT Docomo para a evolução do padrão de interface de redes GSM e na busca por suporte e aceitação internacional desse sistema, por meio de parcerias com outras operadoras da Europa, Ásia e América, e fornecedores de infra-estrutura e aparelhos telefônicos. ${ }^{9}$ Contudo, apesar do predomínio da $3 \mathrm{G}$ com base no padrão GSM, é importante salientar que os padrões $2 \mathrm{G}$ coexistirão por algum tempo. Conseqüentemente, isso implicará a necessidade de suporte e soluções para ambos os padrões (Frenzel, 2001).

\subsection{Evolução dos PDAs e o processo de convergência com a telefonia móvel}

Essa evolução das gerações da telefonia móvel ocorre num ambiente contornado por dois acontecimentos recentes. De um lado há o desenvolvimento de natureza hardware/software; isto é, os avanços consecutivos nos microprocessadores (aumento da capacidade de processamento, com o paralelo aumento da portabilidade, a custos cada vez menores) e o desenvolvimento de softwares com uma interface de trabalho cada vez mais amigável - isto é, que facilitaram crescentemente a interação usuário-computador (user-friendly software). De outro lado há os avanços na possibilidade de digitalização dos diversos tipos de conteúdo informacional, como dados, textos, áudio e vídeo, que antes eram tratados como distintos e gerenciados por tecnologias diferentes. Desse modo, tornou-se possível a transmissão de enormes quantidades de

\footnotetext{
8 A ITU foi fundada em 1865 e tornou-se uma agência das Nações Unidas em 1947. Ela é responsável por recomendar e homologar tratados, normas e padrões internacionais de telecomunicações desenvolvidos por organizações públicas e privadas dos países.

9 Posteriormente, por outro lado, quando Ericsson e Nokia já eram os maiores fornecedores da infra-estrutura GSM e já haviam alcançado ampla difusão, a indústria americana acreditava que o padrão IS 95 CDMA poderia se tornar o padrão mundial, apenas com base na competição de mercado, não necessitando de um outro processo de escolha de padrão (Funk \& Methe, 2001).
} 
ILUSTRAÇÃO 1

Entrantes no mercado de PDA por indústria de origem

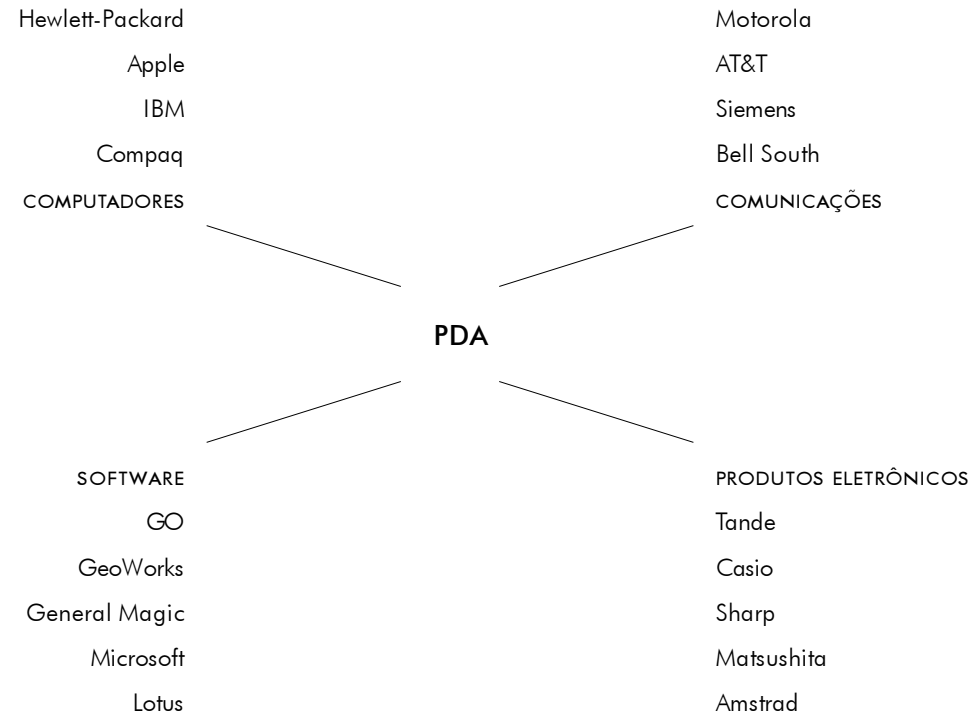

Fonte: Gomes-Casseres \& Leonard -Barton (1997).

informações com elevado padrão de qualidade (tornou-se possível a compressão dos sinais das informaçóes digitalizadas) (Tapscott, 1997).

Por conseguinte, todos esses avanços aumentaram o número possível de aplicações e, conseqüentemente, de oportunidades de negócios de natureza telemática. Um desenvolvimento recente e importante decorre do processo de fusão das trajetórias dos computadores pessoais e dos celulares. Esse processo deu origem a um produto sofisticado, que desempenha funções de computadores e ao mesmo tempo permite acesso às diversas redes de comunicação sem fio, a qualquer tempo e a partir de qualquer lugar. São os conhecidos $\mathrm{PDA}$, handhelds ou handsets. A Ilustração 1 mostra a fusão de competência dos diversos capitais envolvidos na produção do PDA. Veja que anteriormente à convergência cada grupo produzia os seus equipamentos circunscritos a sua área 
de atuação, sem que fosse necessário unir competências para produzir um produto que reunisse atributos de todos estes sistemas. No PDA essas funcionalidades estão todas reunidas num aparelho de bolso (McGahan et al., 1997).

Os pioneiros da trajetória dos PDAs são as primeiras agendas eletrônicas de funções ainda bastante limitadas - introduzidas pelas firmas Sharp e Casio na década de 1980. Mesmo as gerações seguintes, introduzidas na década de 1990, possuíam sérias limitaçōes, como a insuficiente capacidade de conexão com a base instalada de computadores pessoais, além de dificuldades para entrada de dados (McGahan et al., 1997).

Os desenvolvimentos relativos à digitalização de conteúdos, o aperfeiçoamento das redes de comunicação e o aumento da capacidade de processamento desses aparelhos incentivaram a fusão das trajetórias dos celulares, agendas eletrônicas e computadores - esta é a origem aos PDAs. Os pioneiros dessa nova fase foram as firmas Apple e AT\&T. Contudo, essa primeira geração não obteve grande sucesso em função dos preços elevados, da pouca disponibilidade de serviços complementares e da imaturidade do ambiente tecnológico, que se relaciona à pouca disponibilidade de softwares aplicativos específicos e à limitada e dispendiosa capacidade de comunicação (McGahan et al., 1997). Tratava-se de um ambiente imaturo justamente por explorar uma nova trajetória tecnológica decorrente da fusão de várias outras incorporadas em produtos desenvolvidos em separado. Nesse sentido, todos os outros desenvolvimentos de acessórios e aplicativos compatíveis implicariam algum tempo relacionado ao surgimento de novos conhecimentos integrados, bem como a formação de outros arranjos cooperativos para a conjunção de competências de firmas produtoras desses aplicativos. Ou seja, dado o tamanho dos novos arranjos, a mobilidade se reduziu relativamente e o ambiente demandou mais tempo para propiciar a integração tecnológica (Ilustração 2).

Nesse amadurecimento do ambiente, a Apple, por se tratar de uma firma originária da indústria de computadores, lançou aparelhos marcados pela integração comunicação/informática. Assim, seu primeiro produto, o Newton, apesar do conceito original de um aparelho de comunicação pessoal com as capacidades de processamento relativas a um minicomputador, foi marcado por sua limitada capacidade de comunicação, além da pouca compatibilidade com a base instalada de computadores. Outro obstáculo a sua difusão foi a 


\section{ILUSTRAÇÃO 2 \\ Resumo da dinâmica tecnológica recente que estabelece a necessidade de agregar de competências}

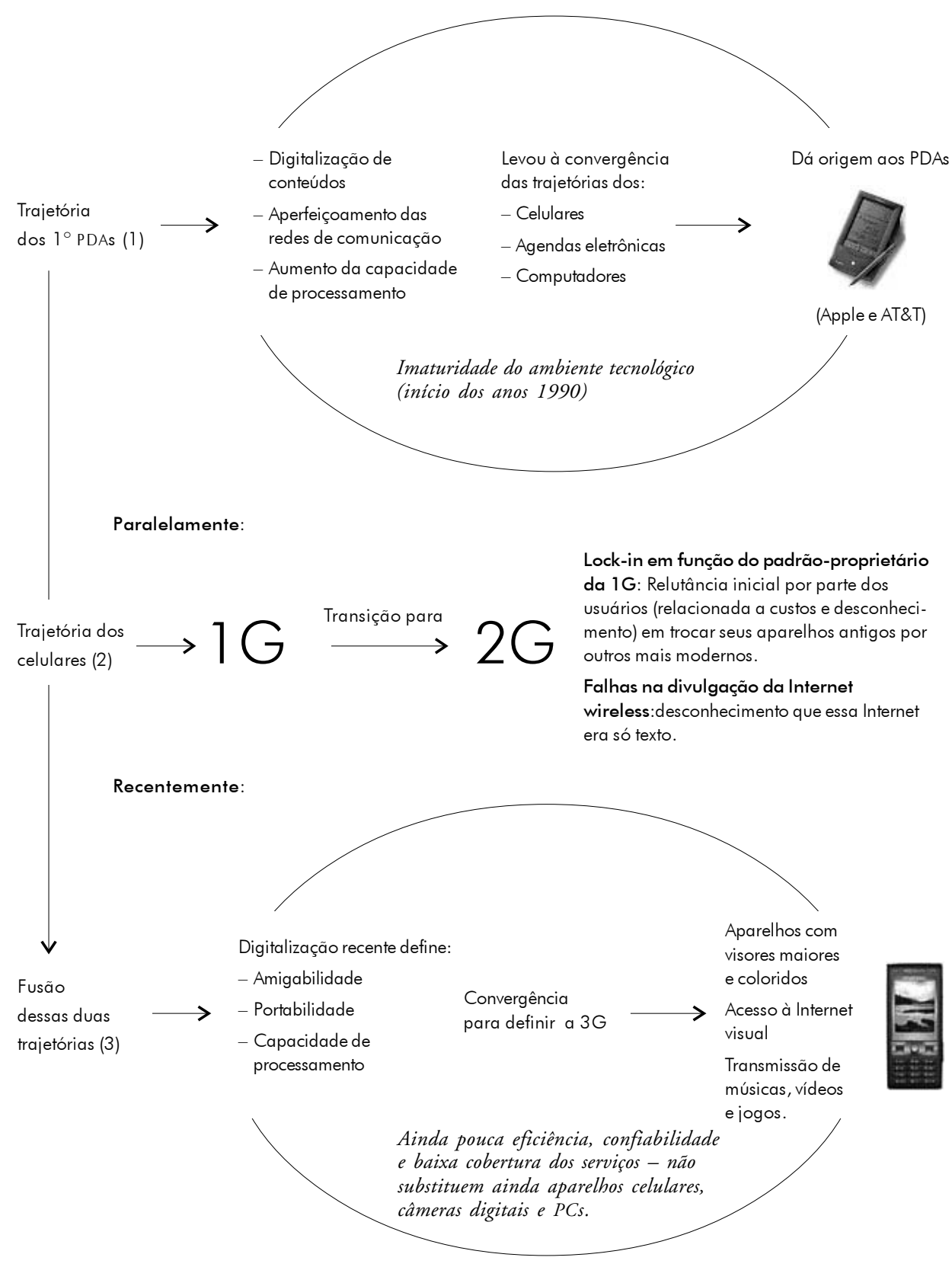


insuficiente oferta de aplicativos, cujo efeito foi reforçado pela fraca amigabilidade ainda prevalecente nestes softwares. Da mesma forma, a AT\&T, por sua vez, dada sua origem, buscou incorporar em seus celulares o poder de processamento dos computadores. Seus produtos destacavam-se pelas qualidades relacionadas à comunicação, mas falhavam justamente no que se referia às funcionalidades dos computadores pessoais. As principais fraquezas de seus produtos referiam-se ao tamanho, ao peso exagerado dos aparelhos, à baixa compatibilidade com a base instalada de computadores, bem como pela oferta insuficiente de aplicativos complementares, aqui também caracterizados pela fraca amigabilidade dos softwares oferecidos. Mesmo os aperfeiçoamentos realizados posteriormente não foram suficientes para consolidar esses produtos no mercado (McGahan et al., 1997).

Por parte da telefonia móvel, após o avanço das redes, de analógica para digital (1G para a $2 \mathrm{G}$ ), um fato que complicou ainda mais esse processo de difusão dos aparelhos que concentram as funções de computadores pessoais e celular foi a dependência relacionada ao desenvolvimento das gerações e dos padróes-proprietário. Como dito anteriormente, na medida em que os padrões-proprietário foram mecanismos de garantir market-share das operadoras e impor trajetórias específicas do desenvolvimento dos serviços aos usuários, acabou-se criando uma determinada situação de lock-in em que as operadoras tornaram-se reféns das suas próprias estratégias, impedindo ou restringindo o desenvolvimento de novas trajetórias. Mais especificamente, a conseqüência dos padrões-proprietário foi que mesmo após o surgimento da $2 \mathrm{G}$ houve relutância inicial por parte dos usuários (relacionada a custos e desconhecimento) em trocar seus aparelhos antigos por outros mais modernos que permitiam acesso a um novo tipo de serviço de texto. Era a possibilidade de acesso à internet. Ademais, falhas na divulgação desses serviços, quando do seu lançamento, por parte da indústria, fizeram com que os consumidores pensassem que a internet móvel de então seria uma experiência comparável à da internet fixa, enquanto que se tratava apenas de um serviço de texto (Forbes, 2001). E isso é bem diferente de se ter à disposição a dinâmica do conteúdo de uma página de internet, com animações, fotos e vídeos no visor daqueles celulares que eram ainda monocromáticos e de tamanho insuficiente para suportar tais aplicações (Ilustração 2). 
Mais recentemente, com o desenvolvimento da digitalização, a convergência vem caminhando em direção à maior portabilidade, capacidade de processamento e amigabilidade. Com isso, a indústria de telefonia móvel tem caminhado para a $3 \mathrm{G}$, dominada por aparelhos com visores maiores e coloridos, com capacidade de troca de mensagens de texto, acesso à internet, agora não apenas no formato texto, mas no formato de multimídia de banda larga, possibilitando a transmissão de músicas, vídeos e jogos. Apesar de atualmente a $3 \mathrm{G}$ ainda se apresentar pouco atrativa em termos de eficiência, confiabilidade e cobertura dos serviços, a ponto de não estar substituindo aparelhos celulares, câmeras digitais e computadores pessoais, o seu significado, no curto prazo, é a difusão dos PDAs a partir da oferta de serviços telemáticos numa perspectiva de portabilidade e maior amigabilidade sustentadas pela alta capacidade de processamento de informações (Ilustração 2).

Nesse momento inicial da junção das diversas competências para a produção dos PDAs, as estratégias dos produtores diferem bastante, tanto em termos da escolha dos parceiros de desenvolvimento, quanto às hipóteses formuladas com relação ao comportamento dos consumidores em potencial. Trata-se justamente de uma situação de incerteza inicial de diversas ordens, decorrente da inovação radical que implica complexidade do desenvolvimento de um novo mercado, complementaridade com produtos já consolidados e indefinição de um padrão tecnológico aberto.

\subsection{Inovação e padronização}

Como se depreende do exposto nas seções antecedentes, os PDAs são produtos que se caracterizam pela sustentação de fortes relações de complementaridade com outros produtos, não obstante inexista qualquer relação de proporçôes fixas nesse consumo. Estes produtos são descritos como sistemas por se referirem a conjuntos formados por dois ou mais componentes que trabalham em conjunto devido à utilização de uma interface particular. Assim, por exemplo, os celulares são um subsistema do sistema de telecomunicação móvel e os pacotes de softwares são subsistemas do sistema de computadores como um todo. Em tais casos, a competição se dá entre sistemas, de forma distinta da competição entre produtos individuais e que envolve três aspectos 
principais (Katz \& Shapiro, 1994): (i) expectativas decorrentes da integração dos agentes a determinado sistema; (ii) requisitos que envolvem a coordenação das decisões necessárias para a operação destes sistemas; e (iii) condiçõos de compatibilidade entre produtos e sistemas.

No caso de sistemas, os consumidores formam expectativas sobre as condições futuras - de disponibilidade, preço e qualidade dos componentes - que enfrentarão. Tal preocupação é decorrência dos custos associados a investimentos específicos, requeridos para a integração dos agentes nessas redes, uma vez que se tenha escolhido um sistema. É que esses investimentos tornam a mudança custosa (os switching costs).

Seria de se esperar, então, que, nessas situações, quando um dado sistema tornar-se mais popular, o efeito sobre a decisão de consumo seria o de privilegiar tal sistema (positive feedback effect). No entanto, estes custos serão mais ou menos importantes em função da intensidade do "excesso de inércia" e de seu oposto, "fricçōes insuficientes", que orientam a seleção de um determinado sistema (Katz \& Shapiro, 1994).

Contudo, através da explícita coordenação dos investimentos para a expansão da rede, contemplando também estratégias para a atração de novos consumidores para a rede, é possível influir na intensidade da "inércia". ${ }^{10}$

Ademais, uma terceira questão relaciona-se à compatibilidade e/ou interoperabilidade dos componentes do sistema. Mais especificamente, ainda que a possibilidade de competição entre sistemas incompatíveis não seja excluída, a integração hardware/software possui algumas propriedades que reforçam a busca de uma maior compatibilidade. Economides (1996:676) argumenta que "it is compatibility that makes complementarity actual". Por outro lado, Katz \& Shapiro (1994:95) enfatizam que apesar de compatibilidade ter benefícios óbvios, a obtenção e manutenção da compatibilidade sempre implicam sacrifício em termos de variedade de produto e restrição à inovação.

\footnotetext{
10 Dentre as mais variadas alternativas estratégicas que podem ser mobilizadas, é possível citar (Katz \& Shapiro, 1994: 103-4): (i) montagem de sistemas abertos, ainda que apenas parcialmente, em termos da estrutura de hardware/software, possibilitando pontos de entrada para novas firmas; (ii) aluguel de hardware em substituição a estratégias de vendas; (iii) integração vertical ou estabelecimento de alianças e contratos de longo prazo para o fornecimento de hardware/ software; (iv) realização de sunk-investments pelo provedor da rede como forma de explicitar compromisso com a continuidade do desenvolvimento de novas soluções; ( $v$ ) adoção de preços de penetração baseados numa redução dos preços de componentes como forma de induzir a expansão da rede; (vi) uso da reputação como "ativo" como meio de intensificar a identificação do proprietário da rede em relação aos consumidores interligados à rede.
} 
Assim, questóes importantes surgem sobre como e se o mercado determina o nível correto da compatibilidade. Portanto, a busca de compatibilidade entre padrōes e interfaces tem efeitos mesmo no planejamento do produto, ou seja, no processo de inovação, anteriormente à produção propriamente dita. ${ }^{11}$

Os benefícios da compatibilidade, quando se tratar de extensas redes de comunicação, fundamentalmente referem-se à possibilidade de compartilharemse recursos disponíveis de diversas redes, racionalizando o uso desse recurso, não incorrendo em custos de duplicação das mesmas a cada nova entrada. Já para o caso das redes em que há a integração hardware/software, no final das contas, os benefícios da compatibilidade estão associados à redução dos custos de produção, seja pelo melhor aproveitamento de economias de escala ou pelo efeito dinâmico do aprendizado ou na forma de spillover tecnológico no desenvolvimento e produção de componentes específicos. Ademais, a compatibilidade entre sistema permite a combinação de diversas tecnologias na medida em que o acesso e as combinaçóes possíveis dos componentes disponíveis possibilitam a diversificação da oferta via ampliação das opções de desenvolvimento de novos componentes e serviços.

Ademais, admitindo-se a existência de externalidades de rede, na medida em que a demanda de um consumidor geralmente é influenciada pelo número de outros consumidores usuários do produto (externalidade direta); pela capacidade de se comunicar com os demais dispositivos com funções complementares e pela maior ou menor disponibilidade de uma ampla variedade de produtos e serviços complementares (externalidade indireta), criam-se fortes pressões sobre as firmas por interfaces padronizadas de interação hardware/ software desenvolvidos em indústrias separadas.

Assim, além de facilitar o enfrentamento das incertezas de mercado, reforça-se a vantagem decorrente do ganho de escala no desenvolvimento de projetos seqüenciais e, por conseguinte, as firmas fora dessa trajetória de desenvolvimento aberto e conjunto, podem estar condenadas a sair da indústria por não conseguirem se beneficiar da mudança tecnológica dentro de uma trajetória especifica (porém, aberta) (Tassey, 2000; Funk \& Methe, 2001).

\footnotetext{
1 Katz \& Shapiro (1994:109) diferenciam dois tipos de compatibilidade: (i) a compatibilidade horizontal, existente entre dois sistemas rivais, e (ii) a compatibilidade vertical, que está associada a gerações sucessivas de uma tecnologia similar.
} 
Por seu turno, os custos associados ao incremento da compatibilidade dependem dos mecanismos através dos quais ela é alcançada. De forma geral, há uma distinção entre dois mecanismos básicos de obtê-la (Katz \& Shapiro, 1994): (i) a utilização de mecanismos de padronização, quando os sistemas são configurados de maneira a utilizar componentes intercambiáveis; e (ii) o uso de adaptadores que interligam componentes de diferentes sistemas, criando assim uma interface entre eles. Aqui, a opção por uma alternativa envolve não somente os custos da busca da compatibilidade, mas também o efeito primário da perda de variedade que padronização implica ou mesmo a possível piora no desempenho do sistema.

Compatibilidade entre componentes e equilíbrio em seus requisitos de desempenho exerce forças restritivas no desenvolvimento do sistema como um todo. Dentro dessa ótica de inovação sistêmica, em que produtos e serviços estão interconectados uns aos outros oferecendo uma ampla gama de funções complementares que não estariam disponíveis de forma independente, uma inovação induz inovaçôes em outras atividades complementares. Ao mesmo tempo, induz à geração de novas combinações físicas dos produtos, softwares e serviços de maneira que a competição não mais ocorre através da introdução de inovaçóes isoladas ou independentes em produtos e serviços, mas de modo sistemático com a combinação de hardware, software e serviços. Desse modo, essa combinação de um elemento do conjunto com outros complementares, abre novas oportunidades e novos mercados (Baba \& Imai, 1992).

Vários outros produtos eletrônicos, como o rádio FM, os audiocassetes, os videocassetes e os compact discs, que também apresentam essa característica de interconexão com outros produtos, antes de alcançarem ampla difusão, necessitaram do estabelecimento de padróes tecnológicos. As lições obtidas, para acelerar a aceitação dos PDAs, são a necessidade de se estabelecer padrões tecnológicos e a importância da interação com a base instalada de produtos relacionados. Nesse sentido, dada a total incerteza sobre a dinâmica da inovação, as vantagens dos first-movers estariam totalmente dissolvidas devido à lentidão no desenvolvimento de um mercado totalmente novo, e ao elevado risco com as amplas possibilidades da imitação por parte dos concorrentes. Nenhuma firma construiu ainda uma base de tamanho suficiente para garantir um poder de mercado e, por conseguinte, não se consolidou ainda alguma imagem forte $o$ 
suficiente para garantir que PDAs similares e alternativos não venham a ameaçar a posição dos first-movers. Por exemplo, a Motorola, Casio, Sony, IBM e outras vêem sistematicamente introduzindo diversos tipos e versões de PDAs (McGahan et al., 1997). ${ }^{12}$

Por um lado, pode-se destacar que se trata de uma situação diferente do desenvolvimento de padrões-proprietário. Nesses, o fundamento não é a abertura da arquitetura dos produtos e sim o fechamento e a imposição de padrões de desenvolvimento para eventuais outros produtores de produtos e soluçôes complementares. Trata-se de uma situação de lock-in dos agentes e, conseqüentemente, eventual esgotamento do desenvolvimento da trajetória tecnológica desses padrões, dado que não há troca de ativos, portanto, não há complementaridade em direção a expansão do sistema como um todo, ou mais precisamente, a criação de uma dimensão de inovação sistêmica. Nesse sentido, ao considerar que os diversos tipos de PDAs se comunicam e transferem dados entre si, de fato há um desenvolvimento de uma rede aberta.

Por outro lado, diante da complexidade tecnológica, especialmente por seu caráter sistêmico, o número e a variedade de padróes desenvolvidos para permitir a interoperabilidade dos equipamentos componentes do seu sistema têm aumentado. Isso porque, mesmo sendo sistêmicas, algumas inovações são mais difíceis de ser incorporadas. Portanto, tais padróes influenciam a estrutura do mercado, a produtividade e a atividade inovativa (Kano, 2000). Assim, a definição e o estabelecimento de padrões atuam não apenas como uma das condições para o sucesso de alianças já estabelecidas, mas também como elemento direcionador na busca de novas alianças. Desse modo, do ponto de vista dos diversos aplicativos disponíveis para cada tipo de PDA estar-se-iam constituindo múltiplas redes proprietárias. Por exemplo, os PDAs da Sony-Ericsson usarão aplicativos produzidos pelo conjunto de firmas de mídia da Sony, que

\footnotetext{
12 Baseando em Katz \& Shapiro (1994) é possível imaginar que nenhuma firma conseguiu ainda estabelecer um tamanho de rede própria que fosse maior e dominante em relação às demais em função de que, em sendo todas pertencentes a uma estrutura oligopolizada (com amplo poder de monopólio) estariam com o seu preço de entrada (preço do aparelho PDA em si) muito acima do custo marginal, o que estaria mantendo relativamente reduzido o tamanho das redes. Desse modo, imagina-se também que não haveria como estabelecer um determinado nível de preço de uso (preço dos diversos softwares e serviços on-line) por conta da ainda pouca informação disponível, pelo tamanho da rede, dos supostos benefícios aos usuários. Desse modo, ainda haveria múltiplos equilíbrios e a questão é que esses diversos players estariam ainda trabalhando em tornar crível que suas redes serão bastante amplas. Se tornar-se-á efetivamente crível não se sabe, mas a questão é que o fato de que cada uma esteja lançando tipos e versões diferenciadas podem afastar o consumidor por medo de ficar locked-in em algum dos tipos de PDA.
} 
obviamente, não são possíveis de serem usados em outro tipo de equipamento. Da mesma forma, os aplicativos usados pelo PDA da Motorola serão produzidos pelo conjunto de firmas que compõe a sua rede de fornecedores de software e que também são proprietários. A questão fundamental é que fora a comunicabilidade, a tendência é a de perpetuar esses diversos padrões por conta dos diversos atributos que cada PDA possui e que são buscados pelos mais diversos tipos de consumidores. Talvez, por conta da natureza do produto, para o consumidor é mais importante a especificidade do que cada produto em si tem a oferecer (serviço, jogos disponíveis, agenda, comunicação, aplicativos, etc.) do que o tamanho da rede. Em outros termos, a não padronização beneficia a ampla variedade possível de novos serviços e aplicativos para os diversos tipos de PDAs. Essa é a mesma razão porque historicamente não se estabeleceram a padronização em diversos segmentos, como Apple vs. PC e VHS vs. Beta. ${ }^{13}$ Ademais, como se trata de players importantes, onde a marca é um ativo específico importante a proteger, o lançamento de PDA associa-se a ela e à tentativa de tornar crível de que esse produto tem amplas possibilidades de expansão em termos de novos usuários e disponibilidade de aplicativos e suas diversas geraçóes. Se a compatibilidade fosse uma meta importante, o ativo marca tornarse-ia irrelevante uma vez que, para o consumidor ela não seria importante em função de que qualquer PDA não implicaria risco de escolher uma tecnologia errada ou de ficar locked-in numa rede proprietária muito pequena (Katz \& Shapiro, 1994).

Em função dessa crescente convergência tecnológica, incertezas de mercado e conseqüente fusão de competências derivadas da emergência desses diversos subsistemas inter-relacionados, as firmas não estão mais conseguindo,

\footnotetext{
13 David (1993), utilizando-se de um problema ilustrativo (snow-shoveling), procura ressaltar as características os processos de mudança path-dependent. Neste trabalho o referido autor argumenta que um processo path-dependent é nãoergódico no sentido de que a transição entre estados o sistema é função da seqüência de estados transitórios passados. Ademais, ele chama atenção para a natureza localmente limitada (locally bounded) do efeito das externalidades de rede sobre as escolhas individuais, no sentido de que a racionalidade do processo de escolha dos agentes não é universal, mas específica e determinada pelo contexto. Ou seja, o autor enfatiza a dinâmica macro que surge a partir de processos de decisão no nível micro, de forma que o estado presente é moldado pelas decisões individuais desde o início do processo. Assim, a questão que surge desse modelo é: existe alguma forma de prever que configuração finalmente estabelecer-se-á. Traduzindo o modelo para o tema em questão aqui, entende-se que se trata de uma formalização da afirmação de que não haverá convergência de padrões tecnológicos dos PDAs em função de que pelos mais diversos motivos concorrênciais e tecnológicos a busca de convergências de uns implicará padrões proprietários de outros, de tal forma que, a proporção de padrões proprietários permanecerá relativamente sempre a mesma em relação ao conjunto de fabricantes que convergem seus padrões.
} 
de maneira independente, desenvolver e produzir com excelência em todos os subsistemas. Assim, mais uma vez enfatiza-se a relevância dos acordos cooperativos que passam a ser a estratégia explicita para acelerar o alcance da maturidade tecnológica.

A seção seguinte discute o caso especifico da conjugação de fatores que forçou a união de forças da Ericsson (telecomunicaçôes) e Sony (produtos eletrônicos de consumo) para o desenvolvimento de aparelhos 3G.

\section{O exemplo de agregação de competências ${ }^{14}$ distintas a partir da digitalização: Sony-Ericsson}

Como já ressaltado anteriormente, diante da incapacidade de superar isoladamente todas as incertezas causadas pela convergência digital, muitas firmas estão buscando parceiras. Em muitos casos a eventual rivalidade anterior não impede a combinação de competências para o desenvolvimento e a difusão dos produtos eletrônicos com o expertise em telecomunicaçóes. Geralmente, portanto, essa movimentação tem implicado a formação de complexas redes de alianças que associam grandes grupos de telecomunicações, informática e de produtos eletrônicos. Exemplos dessas alianças são os acordos entre a Siemens e a Toshiba e entre a NEC e a Matsushita (Panasonic) para o desenvolvimento de tecnologia em aparelhos 3G (Wrolstad, 2002).

É nesse sentido, ou seja, na busca da cooperação ideal para tentar moldar as características e acompanhar a trajetória tecnológica do crescimento do mercado de celulares 3G e da internet móvel, que as firmas Sony, líder em produtos

\footnotetext{
14 termo competência usado no texto até aqui se refere à dimensão das "capacitações dinâmicas" da firma. Essa vertente evolucionária da mudança econômica é oriunda dos trabalhos de D. Teece e G. Pisano. Uma exposição detalhada dessa abordagem pode ser encontrada em Teece et al. (1997), por exemplo. Essas competências são entendidas como aquelas competências internas e externas específicas da firma exploradas com o objetivo de enfrentar mudanças no ambiente. $O$ termo "dinâmica" se refere à capacidade de renovar competências de forma a responder às mudanças no ambiente. Já o termo "capacitação" se refere ao papel chave do gerenciamento estratégico em adaptar, integrar e reconfigurar as habilidades organizacionais internas e externas, recursos e competências funcionais, capazes de fazer frente aos requerimentos do ambiente em permanente mudança. Esse entendimento da firma é um desdobramento da visão resource-based strategy da firma. A convergência entre elas é a capacidade de manter e renovar coordenadamente uma estrutura superior em função de menores custos, altíssima qualidade ou desempenho do produto. No caso aqui em questão, essa estrutura fundamenta-se em ativos de alto conteúdo tecnológico/ conhecimento, logo, valioso. Entretanto, a firma possui vantagem competitiva principalmente em decorrência das especificidades inerentes aos serviços e softwares usados pelo hardware (PDA) e não pelo hardware em si (logo a especificidade dos ativos relaciona-se ao aspecto software em geral) e conseqüentemente na sua dificuldade de imitação (Teece et al., 1997).
} 
eletrônicos e em entretenimento pessoal, e a Ericsson, líder em tecnologia de comunicação móvel, formaram uma joint-venture, no ano de 2001, que incorporou seus respectivos negócios mundiais de telefonia móvel.

A joint-venture resultante desse acordo é a firma independente Sony Ericsson Mobile Communications Ltd., com cada companhia detendo uma porção de $50 \%$ do capital da nova firma. A nova firma é a responsável pelos trabalhos de pesquisa e desenvolvimento dos seus produtos, que serão comercializados sob sua própria marca, assim como marketing, vendas, distribuição e serviços ao consumidor (Sony Ericsson, 2001a). Às firmas Sony e Ericsson cabem o suporte e a cooperação com a recém criada joint-venture, conservando, contudo, a independência de suas unidades (Clarke, 2001). Assim, o relacionamento entre as firmas é regulado por um arcabouço contratual, definindo mecanismos de coordenação e de prevenção contra comportamentos oportunistas por parte dos agentes, além de reforçar o comprometimento com os objetivos das partes envolvidas.

Conforme a Tabela 2, a Ericsson é uma das maiores firmas do setor de telefonia móvel e a primeira no mercado total de GSM, mostrando que embora não detenha grande quantidade de direitos de propriedade intelectual sobre padrões de comunicação (Gráfico 3), conseguiu obter sucesso na elaboração de acordos de licenciamento cruzado de tecnologia com outras firmas em função de possuir fortes capacidades internas para o desenvolvimento e apropriação de tecnologias. Isso se justifica na interdependência que se dá entre a existência de capacidades tecnológicas internamente desenvolvidas e a capacidade de absorção de novos conhecimentos e tecnologias externas que se encontram dentro do campo de atuação da firma.

Assim, a partir das competências em telecomunicações da Ericsson, evidenciadas na sua grande participação no mercado mundial de telequipamentos (Tabela 2), aliadas às da Sony em produtos eletrônicos, o arranjo cooperativo desempenha um importante papel no processo de desenvolvimento do mercado desses equipamentos através da transferência e do desenvolvimento conjunto de tecnologias, do acesso a recursos, componentes e a mercados, fatores importantes na difusão de padrões.

Note-se que a partir desse tipo de aliança e da convergência tecnológica, ao mesmo tempo em que se rompem barreiras ao desenvolvimento tecnológico, 
TABELA 2

Participação do mercado GSM, 1996

\begin{tabular}{|c|c|c|c|c|}
\hline Firmas & $\begin{array}{l}\text { Participação no } \\
\text { mercado mundial } \\
\text { de comutação }\end{array}$ & $\begin{array}{l}\text { Participação no } \\
\text { mercado mundial } \\
\text { de estações }\end{array}$ & $\begin{array}{l}\text { Participação no } \\
\text { mercado mundial } \\
\text { de terminais }\end{array}$ & $\begin{array}{l}\text { Posição no } \\
\text { mercado total } \\
\text { de GSM }\end{array}$ \\
\hline Ericsson & $48,00 \%$ & $37,00 \%$ & $25,00 \%$ & $1^{\circ}$ \\
\hline Nokia & $14,00 \%$ & $22,00 \%$ & $24,00 \%$ & $2^{\circ}$ \\
\hline Siemens & $21,00 \%$ & $2,00 \%$ & $9,00 \%$ & $3^{\circ}$ \\
\hline Motorola & $1,00 \%$ & $13,00 \%$ & $20,00 \%$ & $4^{\circ}$ \\
\hline Alcatel & $10,00 \%$ & $10,00 \%$ & $6,00 \%$ & $5^{\circ}$ \\
\hline Lucent & $2,00 \%$ & $4,00 \%$ & $0,00 \%$ & $6^{\circ}$ \\
\hline Matra & $2,00 \%$ & $3,00 \%$ & $0,00 \%$ & $7^{\circ}$ \\
\hline Italtel & $0,00 \%$ & $5,00 \%$ & $0,00 \%$ & $8^{\circ}$ \\
\hline Nortel & $1,00 \%$ & $0,00 \%$ & $3,00 \%$ & $9^{\circ}$ \\
\hline Philips & $0,00 \%$ & $2,00 \%$ & $0,00 \%$ & $10^{\circ}$ \\
\hline Orbitel & $0,00 \%$ & $2,00 \%$ & $0,00 \%$ & $11^{\circ}$ \\
\hline Outras & $1,00 \%$ & $0,00 \%$ & $13,00 \%$ & - \\
\hline
\end{tabular}

Fonte: Bekkers \& Liotard (1999) citado por Bekkers et al. (2002).

surgem novas oportunidades de negócios. A partir da Sony, a Ericsson poderá retomar o projeto de desenvolvimento de um console de jogos em 3D para seus aparelhos, o qual estava paralisado por ter se chegado a uma situação de esgotamento da suas capacidades de desenvolvimento. Faltavam-lhe competências específicas (Rea, 2001). Por outro lado, a Sony adquire vantagens na medida em que complementa conhecimentos para aliar comunicação e entretenimento. Portanto, desenvolve um produto eletrônico de consumo com potência em capacidade de comunicação e difunde seus novos produtos com esse novo conceito a partir da liderança de mercado da Ericsson. Mais especificamente, a aliança fornecerá à Sony parte importante da tecnologia necessária ao 
GRÁFICO 3

Participação da firmas nos direitos de propriedade intelectual dos padrões de GSM

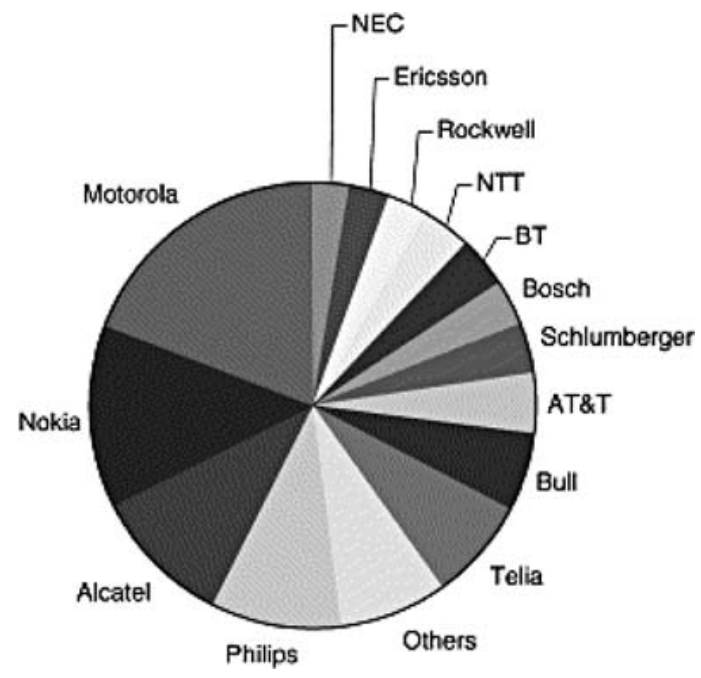

Fonte: Bekkers etal. (2002).

fortalecimento de seu segmento de aparelhos de comunicação móvel, que é o ponto fraco em seu projeto de integração estratégica da sua cadeia de valores em torno dos segmentos de computadores pessoais, TV digital por satélite, jogos e, por último, de telefonia móvel (Clarke, 2001).

Em outros termos, o que se está afirmando aqui é que a história das firmas é importante e que o passado determina fortemente as decisões futuras. $\mathrm{Ou}$ seja, a especificidade dos ativos e capacitaçôes acumulados pela firma restringem sua flexibilidade de tal forma que, no caso específico em estudo, a evolução das duas firmas em separado implicaria evoluir em telecomunicações e produtos de consumo eletrônicos e não para produção de um produto que reunisse as duas competências. Mantidas as condiçōes históricas de cada firma, cada uma estaria lock-in no que fez no passado e seus caminhos futuros estariam fortemente path-dependence disso. Desse modo, essa fusão de competências é o mecanismo fundamental para se estabelecer uma nova trajetória tecnológica em que se rompe os efeitos negativos da path-dependence, mantendo os retornos crescentes de continuar nas tecnologias de telecomunicações e produtos de 
consumo em separado. Note-se que a consolidação das duas firmas é função da construção, ao longo de décadas, desses dois tipos de ativos específicos (produtos de comunicação e produtos de consumo eletrônicos), que definiram uma determinada posição da firma em segmentos relativamente diferentes cuja manutenção implica estratégias que protejam o caráter especifico desses ativos. $\mathrm{O}$ advento da convergência digital, em termos mais gerais, oportuniza a fusão desses ativos e a necessidade de se criar novas competências quebrando o lock-in nas competências especificas e estabelecendo um novo tipo de pathdependence dentro de um novo paradigma tecnológico, qual seja a convergência digital. Ao mesmo tempo essa redefinição mantém a proteção da especificidade dos ativos num novo ambiente tecnológico. ${ }^{15}$ Nesse sentido, uma vez que, que o PDA implica grande número de serviços multimídia a ser produzido pelas diversas firmas da corporação Sony, que obviamente são fortemente protegidos pelo sistema da propriedade intelectual e implicam elevado conhecimento e estrutura de engenharia de software, se trata de um produto de difícil imitação (dado que não é possível a engenharia reversa), perpetua-se um forte regime de apropriação. ${ }^{16}$

Do ponto de vista do mercado apenas, essa aliança também assume bastante relevância na medida em que a Sony consegue maior penetração nos Estados Unidos e Europa e a Ericsson entra no mercado japonês. ${ }^{17}$ Por outro lado, a Ericsson possuía pequena participação no mercado japonês e, ainda mais, perdia terreno para a Nokia (Clarke, 2001). Dadas essas condiçóes, é como se a Sony criasse um novo canal de desenvolvimento e distribuição para seus produtos eletrônicos de consumo com capacidade de comunicação e a Ericsson

\footnotetext{
15 Na construção das competências três fatores são determinantes (Teece et al., 1997): (i) processos gerenciais e organizacionais, que se referem à rotina adotada para a produção e aprendizado; (ii) posicionamento, que é à dotação tecnológica, propriedade intelectual, ativos complementares, clientes e suas relações externas com fornecedores e parceiros; e, (iii) path-dependence, que se refere a história passada da firma, materializada nos seus ativos e capacitações que condicionam fortemente o caminho futuro da tecnologia a seguir, em função dos retornos crescentes. Aqui está se destacando o segundo e terceiro fatores.

${ }^{16}$ Regime de apropriação refere-se à facilidade de imitação. A apropriação é função da facilidade de imitação e da eficácia dos direitos de propriedade intelectual como barreira à imitação. Se o produto é difícil de ser imitado e é fortemente protegido pela propriedade intelectual então o regime de apropriação é forte. O oposto significa que é fraco. E situações intermediárias implica regimes moderados (Teece \& Pisano, 1998). A discussão sobre a apropriabilidade centra-se nos serviços (de natureza soff) e não no hardware em si (o equipamento PDA em si) de relativa facilidade de imitação ou pela produção de algo similar. Veja-se, por exemplo, as diversas marcas desse equipamento que estão no mercado, sustentados em diversos sistemas operacionais de natureza proprietária.

17 Em 2000, a Ericsson detinha 10\% do mercado mundial de celulares (atrás da Nokia e da Motorola) e a Sony detinha uma participação de apenas $1,5 \%$, sendo quase a totalidade representada apenas pelo Japão (Clarke, 2001).
} 
ganhasse reforço para se expandir no Japão. A Sony-Ericsson é exatamente o mecanismo de aliança onde desenvolvimento tecnológico e expansão de mercados são duas estratégias complementares inseparáveis. Ou seja, é impossível discutir essa aliança pensando na dicotomia mercado ou inovação.

Assim, essa combinação de forças permitirá à nova firma uma forte vantagem estratégica, ainda mais se levando em conta as novas oportunidades que devem surgir a partir do crescimento da indústria de telefonia móvel com o desenvolvimento da multimídia de banda larga, onde a capacidade dos aparelhos em lidar com conteúdos como filmes, imagens, fotos e jogos - ou seja, a internet móvel de banda larga - será uma característica crucial para o sucesso desses produtos de $3 \mathrm{G} .^{18}$

Há ainda outro elemento que demonstra a complexidade dessa aliança. A sua formação apenas para o desenvolvimento e produção do aparelho é relativamente simples na medida em que todas as conseqüências (retornos financeiros, problemas técnicos, materiais e equipamentos, etc.) são tangíveis, dado que a razão da aliança é o produto, portanto, também tangível. Entretanto, a partir da incorporação dos avanços na microeletrônica pelas telecomunicações, possibilitando o desenvolvimento de aparelhos com visores maiores e coloridos e também apresentando tons sonoros de melhor qualidade, criaram-se oportunidades para a difusão de aplicações da comunicação móvel multimídia de banda larga. Isto é, simultaneamente, os capitais também buscam mecanismos de alianças para a produção de serviços relacionados a esses novos produtos. A questão que se coloca para as firmas do setor, diante da venda de um bem que é acompanhado da venda de uma série de serviços, é justamente como controlar e conseqüentemente definir o grau de apropriação dos retornos advindos das complementaridades que se estabelecem entre o produto e os serviços que o acompanham (Chesnais, 1996).

\footnotetext{
18 Em outros termos o que se denota assim é que as duas corporações possuem competências distintas, bastante específicas. Isto é, não haveria mecanismos de incentivos e/ou de mercado que permitiriam, isoladamente, a cada uma das duas corporações, quebrar a path-dependence do seu desenvolvimento tecnológico em separado e, por conseguinte, viabilizasse caminhar na direção da convergência digital. Fundamentalmente, esse tipo de relacionamento seria impossível se o assunto de que se trata aqui, que é a cooperação e a evolução para o aprendizado conjunto, estivesse a depender do mercado ou da consideração de que a firma se relaciona externamente a partir do balanço entre os benefícios líquidos que pode obter entrando numa eventual relação contratual (ou não). Portanto, a construção das capacitações implica tempo uma vez que ativos específicos se constroem pelo aprendizado fora da relação de compra e venda, que costuma ser instantânea. Logo as capacitações não decorrem da percepção da firma como mecanismo de nexos de contratos (Teece et al., 1997).
} 
Cabe referir, no entanto, que se os acordos de cooperação, como visto, são uma forma de busca de vantagens competitivas, cuja possibilidade de aprofundamento está condicionada pelas características específicas das tecnologias envolvidas, sua evolução está sujeita também a fatores como o regime de apropriação e a presença de ativos complementares. ${ }^{19}$ Assim, em um ambiente de convergência tecnológica, onde as tecnologias de transmissão, no longo prazo, estão se configurando como substitutas, além de deter acesso a uma determinada tecnologia, será crucial também, na determinação da competitividade das firmas, o acesso e poder decisivo sobre os conteúdos que serão demandados (Borés et al., 2003).

Nesse ponto, outro imperativo para a tomada de decisão de cooperar ou não está incorporado nas propriedades da base de conhecimentos envolvida nessas atividades. Em casos onde prevalece uma base de conhecimento fortemente tácita, menor é a habilidade e a possibilidade de se transferir esse conhecimento a outras firmas ou organizações. Ademais, quanto mais complexo o seu conteúdo, maior é a necessidade de desenvolver mecanismos para a integração dos diversos elementos que a compõe. Assim, conforme pode ser visto a partir do trabalho de Dosi et al., (1993), em casos em que há forte poder de apropriação da inovação e a base de conhecimentos que a sustenta é altamente complexa e em grande parte tácita, as firmas podem ser levadas a formar alianças estratégicas, justamente pela grande dificuldade que se impõe à replicação e transferência desse conhecimento. ${ }^{20}$

Com esse foco, a Sony Ericsson formou parcerias com o grupo de entretenimento da Sony (Sony Pictures, Sony Music e Sony Style Imaging) e com a Turner Broadcasting, por exemplo, para garantir a seus usuários a disponibilidade de jogos, vídeos e tons musicais, ou seja, serviços e aplicativos complementares que adicionam valor a seus produtos (Sony Ericsson, 2002a; Sony Ericsson, 2003b). Note-se, a partir disso, a complexidade decorrente da fusão entre produtos e serviços oferecidos conjuntamente; isto é, não há como se imaginar aparelho e serviços em separados.

\footnotetext{
19 Para uma discussão aprofundada sobre a classificação e importância dos ativos complementares, cf. Teece (1986).

20 Para uma detalhada exposição da tipologia de estratégias das firmas, cf. Dosi et al. (1993). À semelhança de Freeman \& Soete (1997), os autores também definem um conjunto básico de estratégias das firmas. Para a formação deste conjunto, os autores vinculam o potencial e a abrangência das oportunidades tecnológicas e a complexidade da base de conhecimentos envolvida à decisão da firma de especializar-se, diversificar-se, integrar-se verticalmente ou participar de arranjos cooperativos.
} 
Dada a complexidade envolvida nessa relação, um elemento importante na evolução das capacitações é a forte coordenação da integração das rotinas de ambas as firmas no sentido de que elementos e aspectos importantes da dinâmica inovadora de cada uma delas passam a estar integrados para a geração de novas competências. Ou seja, se cada uma delas possuía rotinas específicas para coleta e processamento de informações e P\&D em áreas especificas (comunicação e multimídia em separado), nessa nova organização a rotina de inovação assume uma nova coerência e racionalidade que é dada pela noção de rotina dos processos centrados na convergência tecnológica. Desse modo, ficam estabelecidas as condições para um aprendizado relativo às questôes técnicas da inovação como também interorganizacional, ou seja, criam-se mecanismos de aprendizado sobre o gerenciamento coordenado interorganizacional que pode ser um caminho relevante para a melhoria das rotinas integradas à nova firma e prevenção de pontos falhos, em geral não percebidos individualmente. Obviamente uma reorganização dessa dimensão implica descentralizar e atribuir elevado grau de autonomia à essa nova firma de tal forma que ela possa ajustar-se ao novo ambiente que se cria a partir do novo tipo de PDA, avaliar o mercado e os competidores e transformar-se rapidamente a frente da competição ${ }^{21}$ (Teece et al., 1997).

Outra preocupação que surge a partir dessa aliança relaciona-se à interoperabilidade e à compatibilidade entre seus aparelhos de 3G com as geraçóes anteriores, com produtos eletrônicos, como câmeras digitais, e com a base instalada de computadores. Mais elementos de complexidade aparecem. Tratase das parcerias firmadas com a Apple, Hewlett-Packard (HP), além dos consórcios formados com várias outras firmas, como o Symbian, ${ }^{22}$ que têm a iniciativa primária de permitir a rápida introdução no mercado de produtos e serviços que sejam compatíveis através do desenvolvimento e do licenciamento de interfaces, softwares e de padrões que permitam transmissão e controle dos dados pelos telefones móveis (Sony Ericsson, 2001b; Sony Ericsson, 2002b;

\footnotetext{
21 Coordenação/integração, aprendizado e transformação são elementos do processo gerencial e organizacional; o primeiro fator das competências/capacitações dinâmicas, conforme nota anterior (Teece et al. , 1997).

22 A Symbian é uma companhia composta pela Nokia $(47,9 \%)$, Siemens $(8,4 \%)$, Panasonic $(10,5 \%)$, Samsung $(4,5 \%)$, Ericsson $(15,6 \%)$ e Sony Ericsson $(13,1 \%)$, fundada em junho de 1998 e que tem como objetivos desenvolver e promover o licenciamento de softwares e padrões que permitam transmissão e controle dos dados pelos telefones móveis (Symbian, 2004).
} 
Sony Ericsson, 2003a). Dessa forma, portanto, permite-se a integração de capacidades operacionais e competências organizacionais dos agentes, bem como a compatibilização e integração de tecnologias dos diferentes estágios das cadeias produtivas, evidenciando a divisão do trabalho entre as firmas e a interdependência entre os agentes no interior das redes. Já o conteúdo destas articulações, devido à convergência de tecnologias de diferentes indústrias, engloba a integração de etapas ao longo da cadeia produtiva e a realização de um esforço tecnológico conjunto, encadeando tecnologias e mercados complementares através da integração de conhecimentos e competências dos agentes envolvidos.

Portanto, todas essas movimentaçōes refletem a busca da dominação do mercado na $3 \mathrm{G}$ de aparelhos de celular. No entanto, como apontado anteriormente, o caso da Sony Ericsson não é um exemplo isolado. Devido aos diversos desafios impostos ao desenvolvimento de um sistema totalmente novo e da necessidade cada vez maior de expansão dos mercados em nível internacional, as firmas estão cada vez mais repensando as possibilidades de formarem alianças. Paradoxalmente, ao contrário de resultar em um ambiente menos competitivo, a instabilidade imposta pelo avanço tecnológico e as oportunidades que se abrem para as firmas implica um ambiente extremamente competitivo.

\section{Conclusão}

A partir da concepção de arranjos cooperativos fundamentados na inovação, o artigo mostrou que o desenvolvimento da digitalização impôs a formação desses arranjos entre firmas de computadores, comunicação, software e produtos eletrônicos de consumo para o lançamento de produtos telemáticos que congregam funções relativas a essas áreas. Até se chegar às condições propícias a esse desenvolvimento, essa nova indústria trilhou uma primeira trajetória tecnológica bem diferente. As primeiras gerações de comunicação móvel caracterizaram-se pelos padróes-proprietário que tiveram como conseqüência a divisão regional dos padrões, sem que houvesse uma integração digital entre eles.

Com o progresso técnico das tecnologia de transmissão, permitindo a melhora do desempenho dos serviços e possibilidade de maior velocidade de transmissão, houve conseqüente aumento das subscrições aos serviços de telefonia móvel, declínio dos preços, melhoria do desempenho dos serviços e 
possibilidade de serviços com maior velocidade de transmissão de dados que permite o acesso à internet móvel e até a transmissão de vídeos. A partir da 3G, impôs-se às operadoras a quebra de suas estratégias de lock-in e dependência por meio de padrões-proprietário e a necessidade de se estabelecer padrôes abertos ou compatíveis. Dentro dessa nova perspectiva de arquitetura de sistemas compatíveis, há esforços conjuntos, mas não únicos, entre países e operadoras globais, de desenvolver padrôes de $3 \mathrm{G}$.

Nesse ambiente de integração hardware/software fundem-se as trajetórias dos computadores pessoais e dos celulares, permitindo o acesso às diversas redes de comunicação sem fio, a qualquer tempo a partir de qualquer lugar. A direção do desenvolvimento desses aparelhos aponta para um crescente aperfeiçoamento das interfaces com o usuário (desenvolvimento de user-friendly softwares) e maiores portabilidade e capacidade de processamento. Desse modo, os produtores relacionados à $3 \mathrm{G}$ trabalham para produzir aparelhos com visores maiores e coloridos, com capacidade de troca de mensagens de texto, acesso à internet, agora não apenas no formato texto, mas no formato de multimídia de banda larga, possibilitando a transmissão de músicas, vídeos e jogos. Tratase, portanto, de um novo ambiente tecnológico marcado pela oferta de serviços telemáticos numa perspectiva de portabilidade, amigabilidade e alta capacidade de processamento de informações.

Portanto, todos os produtos de $3 \mathrm{G}$ decorrem, por natureza, de um processo de inovação sistêmica. Assim, produtos e serviços se complementam com uma grande quantidade de serviços que seriam inimagináveis se produzidos de forma independente. De outra forma, pode-se dizer que nesse tipo de arranjo cooperativo, os diversos agentes convergem para o desenvolvimento do produto e softwares acessórios, buscando a complementaridade e a compatibilização, havendo troca de ativos complementares com o objetivo de um crescimento sistêmico da inovação e conseqüentemente, dos agentes envolvidos. Esse é o caso específico, analisado nesse artigo, da junção de competências entre a Sony (japonesa), produtora de bens de consumo eletrônicos e a Ericsson (Sueca), produtora de equipamentos e sistema de telecomunicações. Porém, vale destacar a complexidade desse empreendimento. Ele assume dimensões globais e entre agentes de áreas totalmente distintas, que não seriam minimamente complementares num passado muito recente. Apesar de ser um novo sistema que 
busca a compatibilidade e a integração de sistemas individuais, a $3 \mathrm{G}$ em comunicação celular ainda é uma geração em consolidação, pois os diversos sistemas não são, necessariamente, compatíveis com a base de computadores existentes. Ainda há uma busca de complementaridades e padrões interativos.

Junto com isso, outro aspecto complexo se relaciona à apropriação dos resultados. Na medida em que essas alianças, assim como outras do mesmo tipo, dão origem ao desenvolvimento de serviços complementares a partir de novos agentes econômicos que se integram a elas, a grande complexidade está em como definir graus de apropriação e controle do conhecimento e resultados econômicos de uma atividade onde os limites do tangível e intangível são bastante indefinidos. Cabe referir, entretanto, que as condições de apropriabilidade dos frutos da adoção de estratégias de inovação envolvem, além dos direitos de propriedade intelectual e as capacitações tecnológicas básicas, a posse de ativos complementares. Assim, a partir da crescente convergência digital, que aproxima as tecnologias de transmissão a substitutos técnicos perfeitos, o poder de decisão sobre conteúdos informacionais e softwares torna-se elementochave, essencialmente porque tais elementos apresentam como propriedades críticas o seu caráter tácito e altamente complexo. Sintetizando, esses ativos são de difícil imitação.

Portanto, há uma ampla diversidade de trade-offs que se colocam para a tomada de decisão das firmas. Todavia, diante da forte interdisciplinaridade da base de conhecimentos envolvida nas novas tecnologias, cujo conteúdo é em grande parte tácito, as ligações das firmas umas às outras surge como resposta à necessidade de desenvolvimento de competências tecnológicas em áreas industriais distintas. Além disso, do que foi exposto, as estratégias das firmas estudadas indicam a direção de uma tentativa de se estabelecerem como o elo através do qual os consumidores não apenas obterão um produto, mas também uma vasta gama de serviços complementares. 


\section{Referências bibliográficas}

Baba, Yasunori; Imai, Ken-ichi, "Systemic innovation and cross-border networks: The case of the evolution of the VCR systems", in Scherer, Frederic M.; Perlman, Mark (orgs.), Entrepreneurship, technological innovation and economic growth: Studies in the Schumpeterian tradition, The University of Michigan Press, p.141-151, 1992.

Banerjee, Aniruddha; Ros, Agustin J., "Patterns in global fixed and mobile telecommunications development: a cluster analysis", Telecommunications Policy, v.28, p.107-132, 2004.

Bekkers, Rudi; Duysters, Geert; Verspagen, Bart, "Intellectual property rights, strategic technology agreements and market structure: The case of GSM", Research Policy, v.31, p.1.141-1.161, 2002.

Bekkers, R.N.A; Liotard, L., "The tense relation between mobile telecommunications standards and IPR", European Intellectual Property Review, v.3, p.110-126, 1999.

Bores, C.; Saurina, C.; Torres, R., "Technological convergence: a strategic perspective”, Research Policy, v.23, p.1-13, 2003.

Britto, Jorge, Características estruturais e modus operandi das redes de firmas em condiçōes de diversidade tecnológica. Tese de Doutorado, IE/UfRJ, 1999.

, "Diversificação, competências e coerência produtiva", in Kupfer, David; Hasenclever, Lia, Economia Industrial: fundamentos teóricos e práticas no Brasil, Rio de Janeiro: Campus, 2002.

Brusoni, S; Prencipe A., "Technologies, Product, Organisations: opening the black box of modularity", Industrial and Corporate Change, v.10/1, p.179205, 2001.

Brusoni, S.; Prencipe A.; Pavitt, K., "Knowledge Specialization, Organizational Coupling, and the Boundaries of the Firm: Why Do Firms Know More Than They Make?", Administrative Science Quarterly, 46, p.597-621, 2001.

Castells, Manuel, A sociedade em rede, São Paulo: Paz e Terra, p.209-263, 2003.

Chesnais, François, A mundialização do capital, São Paulo: Xamã, 1996, p.161181. 
Clarke, Peter, Ericsson, Sony to combine mobile handset business, EETimes, 24/4/2001. Disponível em: http://www.eetimes.com/sys/news/OEG20010424S0039. Acesso em: 30/3/2004.

David, P., "Path-dependence and predictability in dynamic systems with local network externalities: a paradigm for historical economics", in Foray, D.; Freeman, C. (orgs.), Technology and the Wealth of Nations, Londres: Pinter Publishers, 1993.

Dosi, Giovanni; Malerba, Franco; Orsenigo, Luigi, "Evolutionary regimes and industrial dynamics", in Magnusson, Lars (org.), Evolutionary and NeoSchumpeterian approaches to Economics, Boston: Kluwer Academic Publishers, 1993.

Economides, Nicolas, "The economics of networks", International Journal of Industrial Organization, n.14, p.673-699, 1996.

Forbes, Jim, Handhels: a pocketful of promise. Disponível em: http://infotrac. galegroup.com/itw/infomark. Acesso em: 30/3/2004.

Freeman, C., "Networks of innovators: a synthesis of research issues", Research Policy, v.20, p.499-514, 1991.

Freeman, C.; Soete L., The economics of industrial innovation, Cambridge/ Massachusetts: MIT Press, $3^{\text {a }}$ ed., 1997.

Frenzel, Louis E., "Driving towards $3 \mathrm{G}$ dell phones: are we there yet?", Eletronics Design, v.19, 2001.

Funk, Jeffrey L.; Methe, David T., "Market- and committee-based mechanisms in the creation and diffusion of global industry standards: the case of mobile communication", Research Policy, v.30, p.589-610, 2001.

Gomes-Casseres, Benjamin; Leonard-Barton, Dorothy, "Alliance clusters in multimedia: Safety net or entanglement?", in Yoffie, David B., Competing in the age of digital convergence, Boston: Harvard Business School Press, 1997.

Gomes-Casseres, Benjamin, "Group versus group: How alliance networks compete", Harvard Business Review, v.72, n.4, p.62-74, julho-agosto, 1994.

Hagedoorn, John; Schakenraad, Jos, "Leading companies and networks of strategic alliances in information technologies", Research Policy, v.21, p.163-190, 1992. 
Hagedoorn, John, "Organizational modes of inter-firm co-operation and technology transfer", Technovation, v.10, p.17-30, 1990.

Hagedoorn, John, "Inter-firm R\&D partnerships: an overview of major trends and patterns since 1960", Research Policy, v.31, p.477-492, 2002.

Henderson R.M.; Clark, K.B., "Architectural Innovation: The Reconfiguration of Existing Product Technologies and the Failure of Established Firms", Administrative Science Quarterly, 35, p.9-30, 1990.

Kano, Sadahiko, "Technical innovations, standardization and regional comparison: a case study in mobile communications", Telecommunications Policy, v.24, p.305-321, 2000.

Katz, M.L.; Shapiro, C., "Systems Competition and Network Effects", Journal of Economic Perspectives, v.8, n.2, p.93-115, primavera, 1994.

Knoke, David; Yang, Song; Granados, Francisco J., "Dynamics of strategic alliance networks in the global information sector: 1989-2000". Disponível em: http://www.soc.umn.edu/-knoke, 2002. Acessado em 10/9/2004.

Mcgahan, Anita M.; Vadasz, Leslie L.; Yoffie, David B., "Creating value and setting standards: The lessons of consumer eletronics for personal digital assistants", in Yoffie, David B., Competing in the age of digital convergence, Boston: Harvard Business School Press, 1997.

Narula, Rajneesh; Hagedoorn, John, "Innovating through strategic alliances: moving towards international partnerships and contractual agreements", Technovation, v.19, p.283-294, 1999.

Prencipe, A., "Technological Capabilities and Product Evolutionary Dynamics: a case study from the aero engine industry", Research Policy, v.25, p.1.2611.276, 1997.

Rea, Darren, Ericsson and Sony link-up could go beyond handsets. Eletronics Times, 2001. Acesso em: 31/3/2004.

Sony Ericsson. Press release. Apple, Cingular \& Sony Ericsson Deliver First Mac to Mobile Solution. Disponível em: http://www.sonyericsson.com, 17/7/ 2002b. Acesso em: 12/11/2004.

, Press release. Nokia and Sony Ericsson to align developer tools for Symbian OS smartphones. Disponível em: http://www.sonyericsson.com, 17/2/2003a. Acesso em: 12/11/2004. 
, Press release. Sony Ericsson and Turner Broadcasting to offer Cartoon Network content for mobile phones. Disponível em: http://www.sonyericsson.com, 3/11/2003b. Acesso em: 12/11/2004.

, Press release. Sony Ericsson announces collaborations with Sony content companies for mobile multimedia. Disponível em: http://www.sonyericsson.com, 5/3/2002a. Acesso em: 12/11/2004.

, Press release. Sony Ericsson, AU-System and Nokia to invest in MMS interoperability. Disponível em: http://www.sonyericsson.com, 30/10/2001b. Acesso em: 12/11/2004.

, Press Releases. Sony and Ericsson Boards approve Joint Venture. Disponível em: http://www.sonyericsson.com, 24/4/2001a. Acesso em: 12/11/ 2004.

Symbian, Company Ownership. Disponível em: http://www.symbian.com/about/ ownership.html. Acessado em 20/10/2004.

Tapscott, Don, Economia digital, São Paulo: Makron Books, p.54-56, 1997.

Tassey, Gregory, "Standardization in technology-based markets", Research Policy, v.29, p. 587-602, 2000.

Teece, David J., "Profiting from technological innovation: implications for integration, collaboration, licensing and public policy", Research Policy, v.15, p.285-305, 1986.

Teece, David; Pisano, Gary, "The dynamic capabilities of firms: an introduction. In: Dosi, G., Teece, D. \& Chytry, J., Technological, organization, and competitiviness - perspectives on industrial and corporate change", Nova York: Oxford University Press, 1998.

Teece, David; Pisano, Gary; Shuen, A., "Dynamic capabilities and strategic management”, Strategic Management Journal, v.18:7, p.509-533, 1997.

Wrolstad, Jay. The trouble with Sony Ericsson. Disponível em: http:// www.wirelessnewsfactor.com, 2002. Acesso em: 12/11/2004.

Yoffie, David B.; Introduction. In: Yoffie, David B.(org.), Competing in the age of digital convergence. Boston: Harvard Business School Press, 1997.

Yoshino, M.Y.; Rangan, S., Alianças estratégicas, São Paulo: Makron Books, 1997, p.3-29. 